University of Louisville

ThinkIR: The University of Louisville's Institutional Repository

Electronic Theses and Dissertations

$5-2012$

\title{
Polychlorinated biphenyl 153 exacerbates nonalcoholic fatty liver disease in C57BL/6 mice.
}

Banrida Wahlang 1986-

University of Louisville

Follow this and additional works at: https://ir.library.louisville.edu/etd

\section{Recommended Citation}

Wahlang, Banrida 1986-, "Polychlorinated biphenyl 153 exacerbates nonalcoholic fatty liver disease in C57BL/6 mice." (2012). Electronic Theses and Dissertations. Paper 1498.

https://doi.org/10.18297/etd/1498

This Master's Thesis is brought to you for free and open access by ThinkIR: The University of Louisville's Institutional Repository. It has been accepted for inclusion in Electronic Theses and Dissertations by an authorized administrator of ThinkIR: The University of Louisville's Institutional Repository. This title appears here courtesy of the author, who has retained all other copyrights. For more information, please contact thinkir@louisville.edu. 


\title{
POLYCHLORINATED BIPHENYL 153 EXACERBATES NONALCOHOLIC FATTY LIVER DISEASE IN C57BL/6 MICE
}

\author{
By
}

\section{Banrida Wahlang}

\author{
A Thesis \\ Submitted to the Faculty of the \\ School of Medicine of the University of Louisville \\ In Partial fulfillment of the Requirements \\ for the Degree of \\ Master of Science \\ Department of Pharmacology and Toxicology \\ University of Louisville \\ Louisville, $\mathrm{KY}$
}

May 2012 
POLYCHLORINATED BIPHENYL 153 EXACERBATES NONALCOHOLIC FATTY LIVER DISEASE IN C57BL/6 MICE

By

Banrida Wahlang

Thesis Approved on

April 04, 2012

By the following Thesis Committee:

Matthew C. Cave, M.D.

Barbara J. Clark, Ph.D.

J. Christopher States, Ph.D.

Gavin E. Arteel, Ph.D.

Russell A. Prough, Ph.D. 


\section{ACKNOWLEDGEMENTS}

I am deeply grateful to my mentor, Dr. Matthew Cave, for his insight and encouragement and Dr. Cameron Falkner, for his continuous support and guidance. They made this thesis possible. My gratitude also goes to my committee members for agreeing to offer their expertise and advice into my project. I am also grateful to my family who has always supported me. 


\title{
ABSTRACT
}

\section{POLYCHLORINATED BIPHENYL 153 EXACERBATES NONALCOHOLIC FATTY LIVER DISEASE IN C57BL/6 MICE}

\author{
Banrida Wahlang
}

April 04, 2012

Polychlorinated biphenyls (PCBs) are persistent environmental pollutants which are detectable in the serum of all American adults. Amongst PCB congeners, PCB 153 has the highest serum level. PCBs have been dose-dependently associated with suspected nonalcoholic fatty liver disease (NAFLD), obesity and metabolic syndrome in epidemiological studies. The purpose of this study is to determine if PCB 153 induces NAFLD in mice fed a control diet (CD), and exacerbates NAFLD in mice fed a high fat diet (HFD). C57BL6/J mice were fed either control or $42 \%$ milk fat diet for 12 weeks with or without PCB 153 coexposure (50 mg/kg i.p. x 4). Glucose tolerance tests were performed, and plasma/tissues were obtained at necropsy for measurements of adipocytokine levels, histology, and gene expression microarrays. In mice fed $C D$, the addition of PCB 153 had little to no effect on any of the measured parameters. In contrast, PCB 153 co-exposure in high fat-fed mice was associated with dramatically increased visceral adiposity, hepatic steatosis and increased plasma adipokines 
including adiponectin, leptin, resistin and plasminogen activator inhibitor-1 levels. Likewise, co-exposure reduced expression of hepatic genes implicated in $\beta$ oxidation while increasing the expression of genes associated with lipid biosynthesis. Regardless of diet, PCB 153 had no effect on insulin resistance or tumor necrosis factor alpha levels. However, HFD+PCB 153 appeared to induce an endoplasmic reticulum (ER) stress response. Therefore, PCB 153 is an obesogen which exacerbates hepatic steatosis; alters adipocytokines; and disrupts normal hepatic lipid metabolism when administered with HFD. Because all U.S. adults have been exposed to PCB 153, this particular nutrient-toxicant interaction potentially impacts on the progression of human NAFLD. 


\section{TABLE OF CONTENTS}

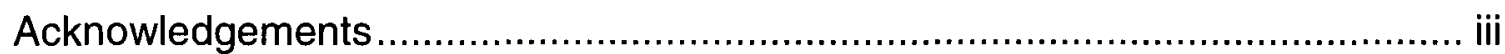

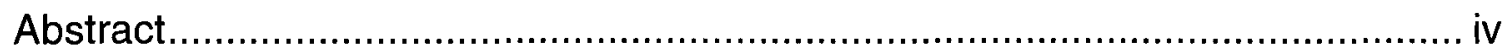

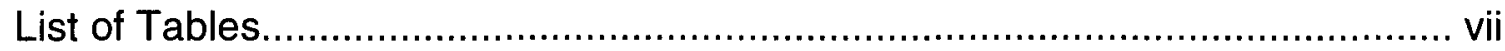

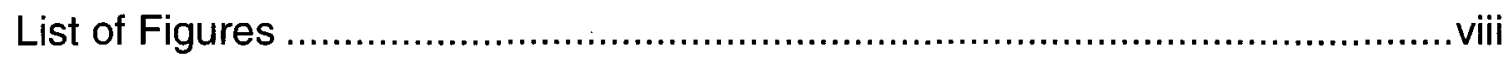

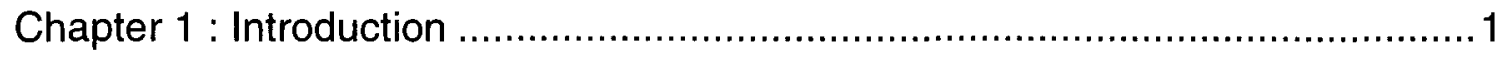

Chapter 2 : PCB 153 worsens diet induced obesity in C57BL/6 mice ..................9

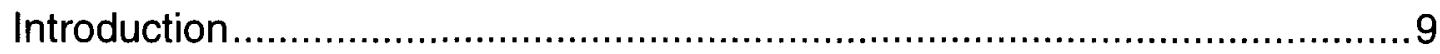

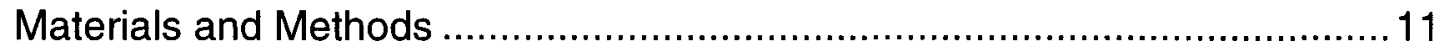

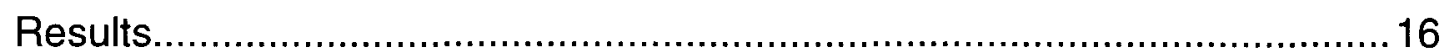

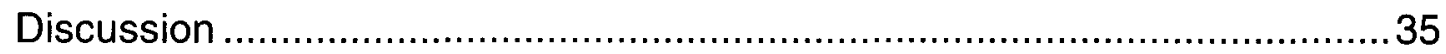

Chapter 3 : Mechanisms by which PCB 153 promote obesity ..........................38

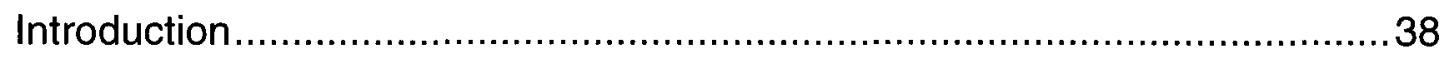

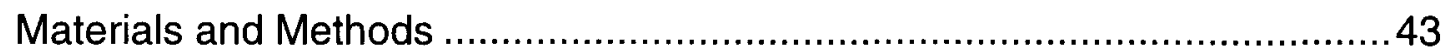

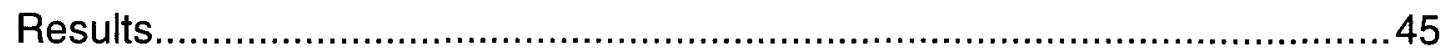

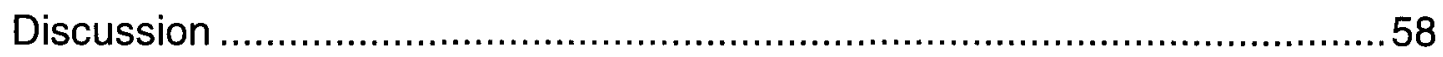

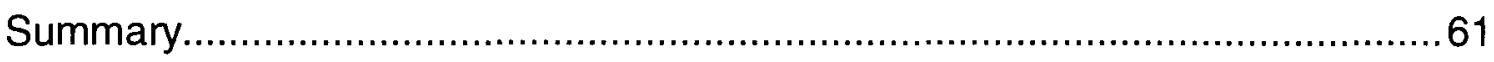

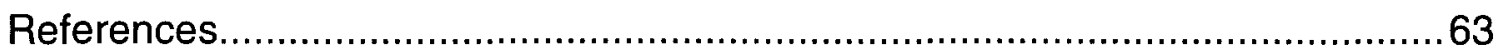

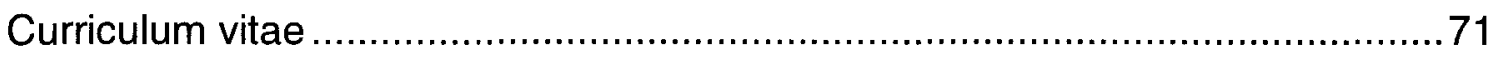




\section{LIST OF TABLES}

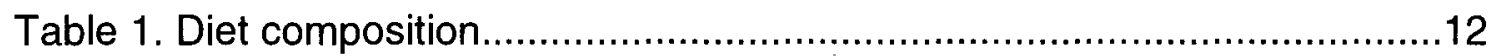

Table 2. Plasma levels of total cholesterol, triglycerides, high density and low

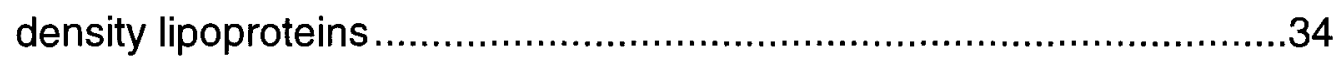

Table 3. Plasma cytokines' and adipokines' levels ......................................46 


\section{LIST OF FIGURES}

Figures

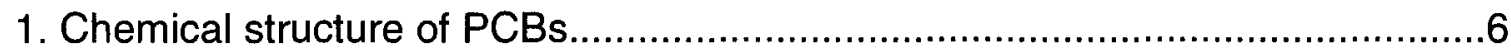

2. PCB 153 increased body weight and visceral adiposity in mice fed HFD.......17

3. H\&E staining showed HFD increased adipocyte cell size and this was unaffected

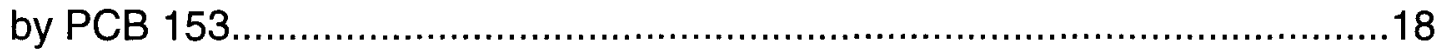

4. HFD increased adipocyte cell size $\left(\mu \mathrm{m}^{2}\right)$ and this was unaffected by PCB 153.

5. Oil Red O staining of liver tissue

6. H\&E staining of liver tissue 23

7. Effects of HFD and PCB 153 on plasma AST levels.............................. 24

8. Effects of HFD and PCB 153 on plasma ALT levels.............................. 25

9. Effects of HFD and PCB 153 on hepatic triglyceride levels...................... 26

10. Effects of HFD and PCB 153 on hepatic cholesterol levels.................... 27

11. HFD increased insulin resistance and this was unaffected by PCB 153 coexposure.

12. Fasting blood glucose levels

13. Glucose tolerance test (GTT). 
14. Area under the curve calculated from GTT.

15. Upregulation of CHOP 10 in endoplasmic reticulum (ER) stress................. 41

16. HFD and PCB exposure altered expression of FAS in liver......................... 49

17. HFD and PCB exposure altered expression of PPARa in liver.................... 50

18. HFD and PCB exposure altered expression of CPT1A in liver.....................51

19. HFD and PCB exposure altered expression of CPT2 in liver...................... 52

20. HFD and PCB exposure altered expression of adiponectin in adipose tissue 54

21. HFD and PCB exposure altered expression of CHOP 10 in adipose tissue...55

22. HFD and PCB exposure altered expression of C/EBPa in adipose tissue.... 56

23. HFD and PCB exposure altered expression of PPARy in adipose tissue..... 57 


\section{CHAPTER 1}

\section{INTRODUCTION}

\section{Polychlorinated biphenyls (PCBs)}

Polychlorinated biphenyls (PCBs) are halogenated compounds consisting of up to 10 chlorine atoms attached to a biphenyl group. They were manufactured during 1930s-1970s and were used as dielectric and heat transfer fluids in electric transformers, wax extenders, flame retardants and as a source of chlorine content. A total of 1.3 million tons of PCBs containing about 130 congeners was manufactured worldwide prior to their banning in 1977 (1). Monsanto, a well-known PCB manufacturer in North America, produced PCB mixtures under the brand name Aroclor at several plants including Anniston, Alabama. High-level environmental contamination during production resulted in increased PCB body burden in Anniston residents (2). Although PCBs have been banned for over 30 years, their high thermodynamic stability make them resistant to chemical degradation in the environment and hence, PCBs, belong to the category of 'persistent organic pollutants' (POPs). PCBs are still present in our ecosystem, including the atmospheric air, lakes, rivers, fish, human adipose tissue, serum and breast milk. Humans are exposed to PCBs through inhalation of PCB-contaminated air or ingestion of PCB-contaminated food. In fact, PCBs continue to be present in the food supply and daily intake in the American diet is 
estimated to be approximately $30 \mathrm{ng} /$ day based on a recent study from a Dallas supermarket (3). PCBs are the 5th most hazardous substances on the CERCLA priority list (2007). The National Health and Nutrition Examination Study (NHANES) indicates that $100 \%$ of adult NHANES participants had detectable circulating PCB levels and PCB $153\left(2,2^{\prime}, 4,4^{\prime}, 5,5^{\prime}\right.$-hexachlorobiphenyl) has the highest median serum concentration in humans amongst all PCB congeners (5).

\section{Non-alcoholic fatty liver disease (NAFLD)}

A previous study from our laboratory group identified suspected nonalcoholic fatty liver disease (NAFLD) and toxicant associated steatohepatitis (TASH) in the NHANES participants with chronic low-level environmental exposures to POPs including PCBs (4). NAFLD represents a pathological spectrum of diseases ranging from lipid accumulation in the hepatocytes (steatosis) to the development of superimposed inflammation (steatohepatitis) and ultimately fibrosis and cirrhosis. NAFLD is the most prevalent liver disease in North America. It resembles alcoholic fatty liver disease although it occurs in non-alcoholic subjects. The pathogenesis of NAFLD has been reviewed (5), and key mechanisms include altered adipo-cytokines with low adiponectin and high leptin levels $(5,6)$ and production of pro-inflammatory cytokines such as TNFa and IL-6 (7). NAFLD gives rise to hepatic insulin resistance and systemic inflammation, which in turn, induces obesity, diabetes and the metabolic syndrome $(8,9)$. Moreover, NAFLD is also exacerbated by diabetes $(10)$ and is associated with obesity (5). Because it is often seen in association with insulin 
resistance and dyslipidemia, NAFLD is generally regarded to be the hepatic manifestation of obesity and the metabolic syndrome. Interestingly, inflamed and fatty liver conditions are not confined to obese individuals only, but other factors can predispose a person to steatohepatitis. Therefore, it is possible that primary factors such as consumption of hyper-caloric foods can lead to steatosis in normal individuals but secondary factors such as POPs can act as a second hit and worsen this effect, leading to a diseased state.

\section{Effects of PCB exposure in humans}

Our laboratory group recently identified advanced steatohepatitis associated with insulin resistance and increased pro-inflammatory cytokines in non-obese chemical workers who were subjected to high-level industrial chemical exposures. The term TASH was then coined to describe this condition (11). Our initial work was focused on TASH in non-obese vinyl chloride workers; in our recent work however, our laboratory group identified suspected NAFLD/TASH in NHANES participants with low-level environmental exposures to POPs including PCBs $(4,11)$. Other epidemiologic studies have found associations between PCBs and metabolic disorders associated with NAFLD including obesity $(12,13)$, insulin resistance/diabetes (14-16), and the metabolic syndrome $(13,17)$. Furthermore, follow-up of subjects involved in the "Yu-cheng" incident in Taiwan, one of the two known major human PCB intoxication episodes, where cooking oil had been highly contaminated by PCBs, the 
mortality rate due to cirrhosis was 2.7 -fold higher than expected (18), although pathologic confirmation was not provided.

\section{Structure-activity and toxicity relationship}

The PCB's structure determines the compound's activity and toxicity. Based on the chlorine substitution in the two phenyl rings, PCBs can be classified as either planar or non co-planar (Figure 1). Planar PCBs have chlorine substitutions in either the meta- or para-positions but not in the ortho-positions. Non co-planar PCBs have ortho- substituted chlorine atoms, apart from metaand/or para-substitutions. PCB studies focused on hepatocarcinogenesis and receptor-based mechanisms including the aryl hydrocarbon receptor (AhR) (coplanar or dioxin-like PCBs), the constitutive androstane receptor (CAR) (noncoplanar or non-dioxin-like PCBs), and more recently, the estrogen receptor (1921). The AhR is a member of the PAS domain protein family of transcription factors and regulates a battery of genes involved with xenobiotic detoxification including CYP1A and CYP1B which can, in turn, bio-transform or activate procarcinogens to their carcinogenic forms. Depending on the type of PCB-receptor interaction, PCBs have a tendency to induce pro-carcinogens leading to carcinogenicity or they can cause hepatomegaly and fatty liver. Coplanar PCBs such as PCB 126 are AhR agonists similar to dioxin (22). Previous work has implicated dioxins and dioxin-like PCBs in animal models of steatohepatitis (23, 24). However, by mass, dioxin-like PCBs are a relatively minor component of the total PCB burden in human serum (4). Moreover, PCBs do not appear to be as 
carcinogenic in man as they are in rodents (eg: PCB 126), and this may be due to differences in the AhR structure and in the battery of target genes between species (25). From a mechanistic standpoint, a PCB's structure determines its ability to interact with nuclear receptors as well. A theoretical structure-activity relationship study predicted that ortho-substituted PCBs can interact with the pregnane-X-receptor (PXR), estrogen receptor(ER), androgen receptor $(A R)$ and thyroid receptor (TR) (26). PCB 153, an ortho-substituted, non co-planar PCB (Figure 1) has been studied extensively by the National Toxicology Program (NTP) in female Harlan Sprague-Dawley (SD) rats and the mode of action has been attributed to the compound's interaction with CAR (27-29). The studies also demonstrated PCB-induced hepatotoxicity $(20,27)$. Furthermore, nutrienttoxicant interactions appear to be important in diet-induced obesity/metabolic syndrome (30) and NAFLD (5). However, the effect of PCB 153, a lipid soluble, non-dioxin like PCB which concentrates in adipose tissue has not been adequately studied in animal models of NAFLD.

PCB's metabolism is defined by the number of chlorine atoms present. Low molecular weight PCBs (mono-, di-, tri- or tetra-chlorinated) are hydroxylated by cytochrome P450 enzymes (31). The metabolized PCBs, also known as biotransformed congeners, can form DNA adducts or bind to proteins to exert their toxic effects. High molecular weight PCBs, on the other hand, do not metabolize, hence they are known as persistent congeners. These PCBs such as the hexa-chlorinated PCB 153, bioaccumulate in the adipose tissue (32). 
Planar

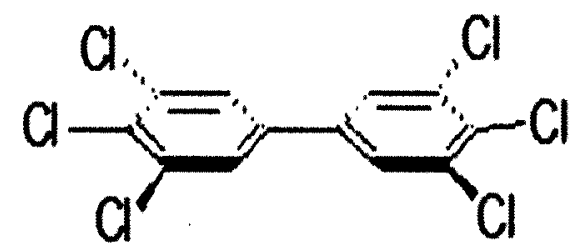

Non co-planar

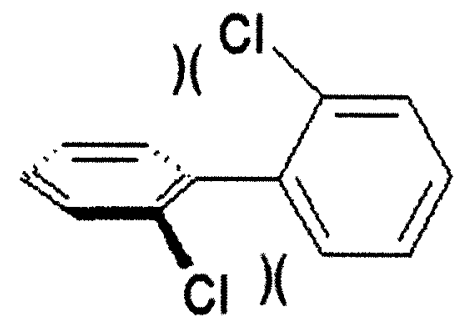

PCB 153

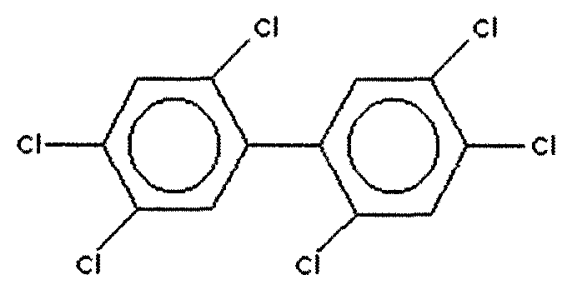

Figure 1. Chemical structure of PCBs. 


\section{Significance of the study}

Obesity has been identified as a leading "preventable cause of death" by the World Health Organization (WHO), and many health authorities view it as one of the most serious health problems of the 21 st century (25). The annual cost of obesity treatment in the US alone was recently estimated at $\$ 147$ billion (1). According to the data from NHANES $2007-2008,33.8 \%$ of US adults are obese (defined by body mass index, $\mathrm{BMI} \geq 30$ ) with another $34.2 \%$ being overweight (defined by $\mathrm{BMI} \geq 25$ ) (26). Alarmingly, obesity is not restricted to the adult population; $15 \%$ of children and adolescents in the US are obese (27).

Overweight/obesity is one of the defining features of metabolic syndrome, a metabolic disorder which is also characterized by insulin resistance, hypertension, and dyslipidemia (28). The prevalence of metabolic syndrome in US adults was recently estimated at $34.3 \%(29)$. The obesity epidemic is strongly associated with increased type 2 diabetes which is the late stage of insulin resistance. The National Diabetes Fact Sheet obtained from the Center for Disease Control and Prevention (CDC, 2011) reports that 25.8 million Americans have diabetes with another 79 million being insulin resistant. Obesity, insulin resistance, and metabolic syndrome eventually lead to target organ damage including fatty liver disease, cardiovascular disease, chronic kidney disease, and cancer.

The pathogenesis of obesity, insulin resistance, and the metabolic syndrome is complex. Historically, obesity was blamed on over-nutrition and 
genetic background. However, recent literature reports implicated NAFLD ( 2 , $30,31)$ and persistent organic pollutants such as PCBs $(3-10,12-15,32)$ as key players in the development of obesity and the metabolic syndrome. 


\section{CHAPTER 2}

\section{PCB 153 WORSENS DIET INDUCED OBESITY IN C57BL/6 MICE INTRODUCTION}

Epidemiologic studies have implicated PCBs in metabolic disorders associated with NAFLD including obesity $(12,13)$, insulin resistance/diabetes (14-16), and the metabolic syndrome $(13,17)$. Moreover, PCB 153 had the highest median serum levels in NHANES participants, than any single PCB congener. It therefore becomes crucial to evaluate the role of PCB 153 in induction of obesity or worsening diet-induced obesity.

In this study, PCB 153 is hypothesized to act as a relevant "second hit" mechanism in the genesis and progression of NAFLD occurring in the context of a high fat diet. The first purpose of this study is to determine, if PCB 153 alone is capable of inducing NAFLD in mice fed a control diet (normal chow diet). The second purpose of the study is to determine if PCB exposures increase NAFLD occurring on a background of diet-induced obesity by worsening previously implicated mechanisms such as insulin resistance.

C57BL6/J mice were used in our 12 week study. The mice were fed either control diet or $42 \%$ milk fat diet with or without PCB 153 co-exposure $(50 \mathrm{mg} / \mathrm{kg}$ i.p. $x$ 4). NAFLD is characterized by hepatic steatosis, inflammation and 
dysregulation in adipokine levels. The objective of our study is to validate if the PCB 153-exposed animals gain weight, showed steatosis, insulin resistance or any other form of metabolic disorder. 


\section{MATERIALS AND METHODS}

Animals and diets. The animal protocol was approved by the University of Louisville Institutional Animal Care and Use Committee. Male C57BL/6J mice (8 weeks old, $n=40$; The Jackson Laboratory, Bar Harbor, Maine) were divided into 4 study groups ( $n=10$ ) based on diet and PCB 153 exposure in this 12 week study utilizing a $2 \times 2$ design. Mice were fed either a high fat diet (HFD, $42 \% \mathrm{kCal}$ from fat; TD.88137 Harlan Teklad) or a control diet (CD, 13.5\% kCal from fat; 5010 LabDiet). Diet composition is shown in Table 1. PCB 153 (Ultra Scientific, North Kingstown, RI), was administered in corn oil (vehicle) by IP injection (vs. corn oil alone) at a dose of $50 \mathrm{mg} / \mathrm{kg}$ on weeks $4,6,8$, and $10(200 \mathrm{mg} / \mathrm{kg}$ of PCB 153 cumulative). This dose was chosen based on previous NTP TR 530 study (3000 $\mu \mathrm{g} / \mathrm{kg}$ by gavage, 5 days per week for 14 weeks $\approx 210 \mathrm{mg} / \mathrm{kg}$ of PCB 153 cumulative) (28). Mice were housed in a temperature-and light-controlled room (12h light; $12 \mathrm{~h}$ dark) with food and water ad libitum. Glucose tolerance tests were performed at week 11, and the animals were euthanized (sodium pentobarbital, $40 \mathrm{mg} / \mathrm{kg}$ body weight, i.p.) at the end of week 12 . Thus four different treatment groups were evaluated in this fashion: CD, CD+PCB 153, HFD, HFD+PCB. 


\begin{tabular}{lcccl}
\hline & \multicolumn{2}{l}{ Control Diet } & \multicolumn{2}{l}{ High Fat Diet } \\
\cline { 2 - 5 } & \%kCal & Source & \%kCal & Source \\
\hline Protein & 28.5 & Soybean Meal & 15.2 & Casein \\
Carbohydrate & 58.0 & Starch/Sucrose & 42.7 & $\begin{array}{l}\text { Sucrose/Corn } \\
\text { starch }\end{array}$ \\
& & & & Milk Fat \\
\hline
\end{tabular}

Table 1. Diet composition. 
Glucose tolerance test. The glucose tolerance test (GTT) was performed 2 weeks prior to the end of study. On the day of test, mice were fasted for $6 \mathrm{~h} \mathrm{(9}$ A.M.-3 P.M.) and fasting blood glucose level was measured with a hand-held glucometer (ACCU-CHEK Aviva, Roche, Basel, Switzerland) using $1 \mu \mathrm{l}$ blood via tail snip. Glucose was then administered ( $1 \mathrm{mg}$ glucose/g body weight, sterile saline, i.p.), and blood glucose was measured at 5, 15, 30, 60, 90 and $120 \mathrm{~min}$ post-injection. Insulin resistance was calculated by homeostasis model assessment (HOMA) using the formula HOMA-IR = Fasting glucose $(\mathrm{mg} / \mathrm{dL}) \mathrm{x}$ Fasting insulin $(\mu \mathrm{U} / \mathrm{mL}) / 405(20)$.

Liver histological studies. Liver sections were frozen using optimal cutting temperature (OCT), a liquid embedding medium, or fixed in $10 \%$ buffered formalin for $24 \mathrm{~h}$ and embedded in paraffin for histological examinations. Tissue sections were stained with either Oil Red O (frozen OCT), hematoxylin-eosin (H\&E; formalin-fixed) or Sirius red stain (formalin-fixed) and examined under light microscopy at $200 \mathrm{X}$ magnification. Photomicrographs were captured using a Nikon Eclipse E600 Microscope.

Liver enzymes, lipids and TNFa mRNA measurements. Plasma aspartate transaminase (AST), alanine transaminase (ALT), cholesterol, triglyceride, high density lipoprotein (HDL) and low density lipoprotein (LDL) levels were measured using Cobas Mira Plus automated chemical analyzer (Roche, Basel, Switzerland). Real-time polymerase chain reaction (RT-PCR) experiments were used to measure hepatic tumor necrosis factor alpha (TNFa) mRNA. Animal liver 
was homogenized and total RNA was extracted using the RNA-STAT 60 protocol (Tel-Test, Austin, TX). cDNA was synthesized from total RNA using the QuantiTect Reverse Transcription Kit (Qiagen, Valencia, CA). PCR was performed on the Applied Biosystems StepOnePlus Real-Time PCR Systems using the Taqman Universal PCR Master Mix (Life Technologies, Carlsbad, CA). Primer sequence for TNFa (Mm00443258-m1) was obtained from Taqman Gene Expression Assays (Applied Biosystems, Foster City, CA). The levels of mRNA were normalized relative to the amount of glyceraldehyde-3-phosphate dehydrogenase (GAPDH) (4352932E). Expression levels in mice fed CD and administered vehicle were set at $100 \%$. Gene expression levels were calculated according to the $2^{-\Delta \Delta \mathrm{Ct}}$ method (33).

Measurement of hepatic triglyceride and cholesterol content. Frozen mouse livers were washed in neutral $1 \mathrm{X}$ phosphate buffered saline and pulverized. Hepatic lipids were extracted by an aqueous solution of chloroform and methanol, according to the Bligh and Dyer method (21), dried using nitrogen and re-suspended in $5 \%$ lipid free bovine serum albumin. Triglycerides and cholesterol were quantified using the Cobas Mira Plus automated chemical analyzer. The reagents employed for the assay were L-Type Triglyceride M (Wako Diagnostics, Richmond, VA) and Infinity Cholesterol Liquid Stable Reagent (Fisher Diagnostics, Middletown, VA) for triglycerides and cholesterol respectively. 
Statistical Analysis. Statistical analyses were performed using GraphPad Prism version 5.01 for Windows and SigmaPlot 11.01. Data are expressed as mean \pm SEM. For 2 group comparison, an unpaired t-test was used, and multiple group data were compared using Two Way ANOVA followed by Tukey Test for posthoc all pairwise comparisons. $\mathrm{P}<0.05$ was considered statistically significant. 


\section{RESULTS}

PCB 153 treatment increased body weight and visceral adiposity in mice fed high fat diet, but had no effect in mice fed control diet.

During the 12 week experiment, all groups experienced weight gain (Figure 2). PCB 153 administration had no significant effect on mean percent body weight gain in mice fed CD $(111.10 \pm 0.75 \%$ for $C D$ vs. $107.50 \pm 1.73 \%$ for CD+PCB 153). In contrast, PCB 153 significantly increased body weight gain in mice fed with HFD $(122.80 \pm 1.98 \%)$ vs. HFD+vehicle $(114.40 \pm 2.56 \%, p<0.05)$. There was a significant interaction between HFD and PCB 153 using Two Way ANOVA $(p=0.002)$.

On H\&E stain, epididymal adipocyte size was increased by HFD, but PCB 153 had no additive effect (Figure 3). In mice fed with CD, the mean epididymal adipocyte area $\left(\mu \mathrm{m}^{2}\right)$ was $1357.95 \pm 70.73 \mu \mathrm{m}^{2}$ with vehicle control and this was significantly increased with PCB $153\left(1806.46 \pm 169.46 \mu \mathrm{m}^{2}, \mathrm{p}=0.02\right)$ (Figure 4). In mice fed HFD, adipocyte size was not significantly different for vehicle $\left(5643.82 \pm 632.49 \mu \mathrm{m}^{2}\right)$ vs. PCB $153\left(5371.29 \pm 484.91 \mu \mathrm{m}^{2}\right)$. However, adipocyte size was significantly larger with HFD+vehicle vs. both $C D+v e h i c l e$ and CD+PCB $153(p<0.05)$. Likewise, mean adipocyte size was larger with HFD+PCB 153 vs. both CD+vehicle and CD+PCB $153(p<0.05)$. Therefore, PCB 153 increased diet-induced obesity, independent of effects on adipocyte size. PCB 153 slightly increased adipocyte size only in mice fed CD. 


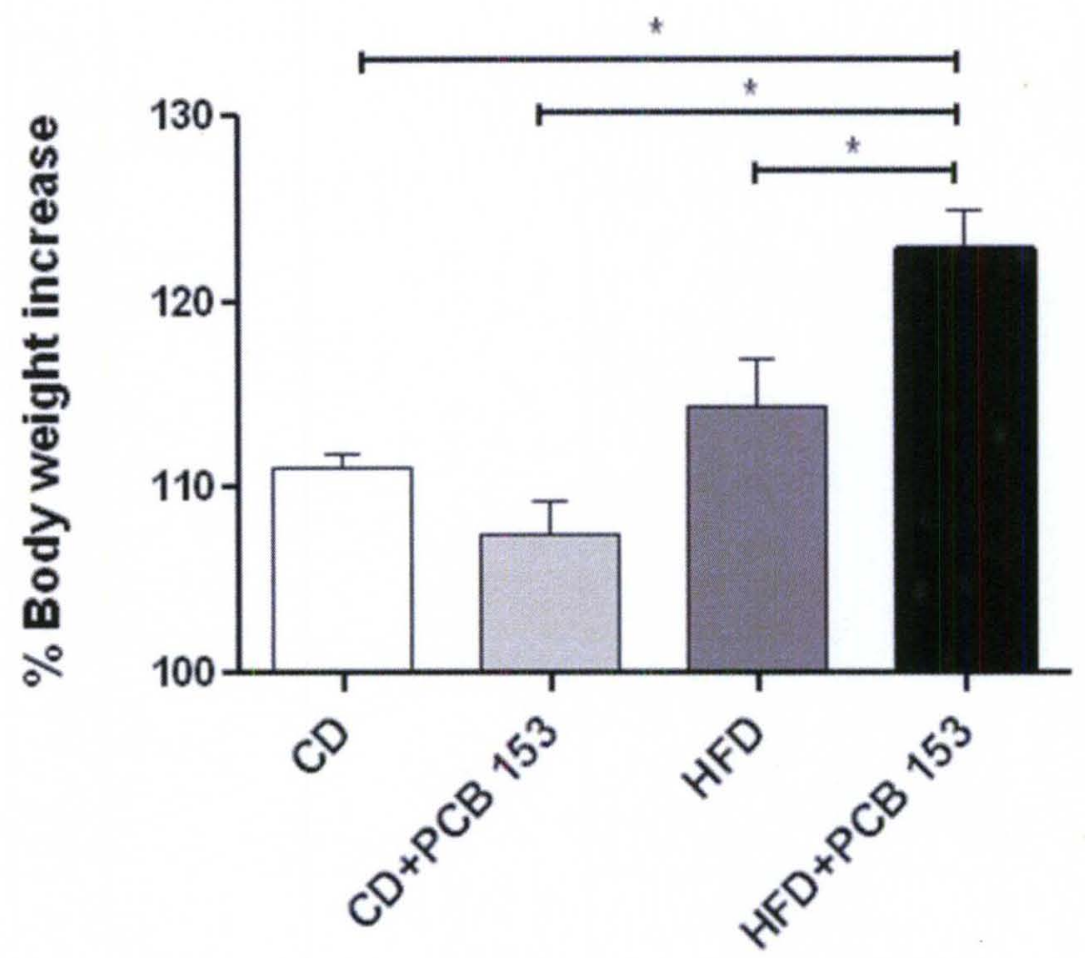

Figure 2. PCB 153 increased body weight and visceral adiposity in mice fed HFD.

The $\%$ increase in body weight for C57BL/6J mice $(n=10)$ treated with a $42 \%$ milk fat diet (vs. CD) \pm PCB 153 (200 mg/kg cumulative). Body weight measurements were taken from week 1 to week 12 (12 weeks) and the body weight at week 1 was taken as $100 \%$. Data are expressed as mean \pm SEM. ${ }^{*} P<0.05$. CD-control diet, HFD-high fat diet, PCB-polychlorinated biphenyl. 


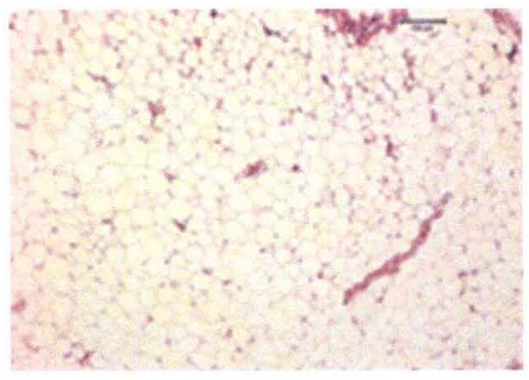

CD

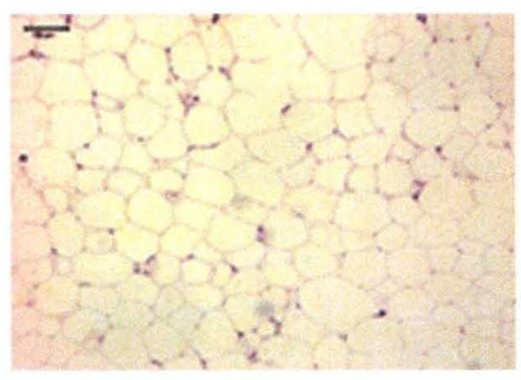

HFD

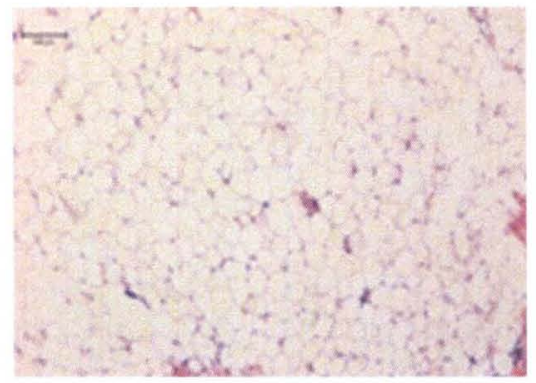

CD+PCB 153

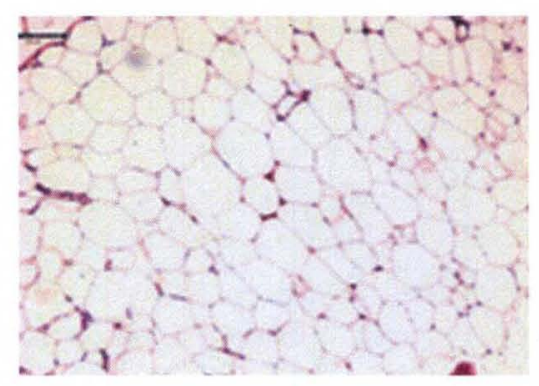

HFD+PCB 153

Figure 3. H\&E staining showed HFD increased adipocyte cell size and this was unaffected by PCB 153.

Epipdidymal adipose tissue was stained with H\&E and images were captured using a Nikon Eclipse E600 Microscope. The adipocyte cell size was increased in mice fed with HFD and this effect was not changed with PCB 153 coadministration. CD-control diet, HFD-high fat diet, PCB-polychlorinated biphenyl. 


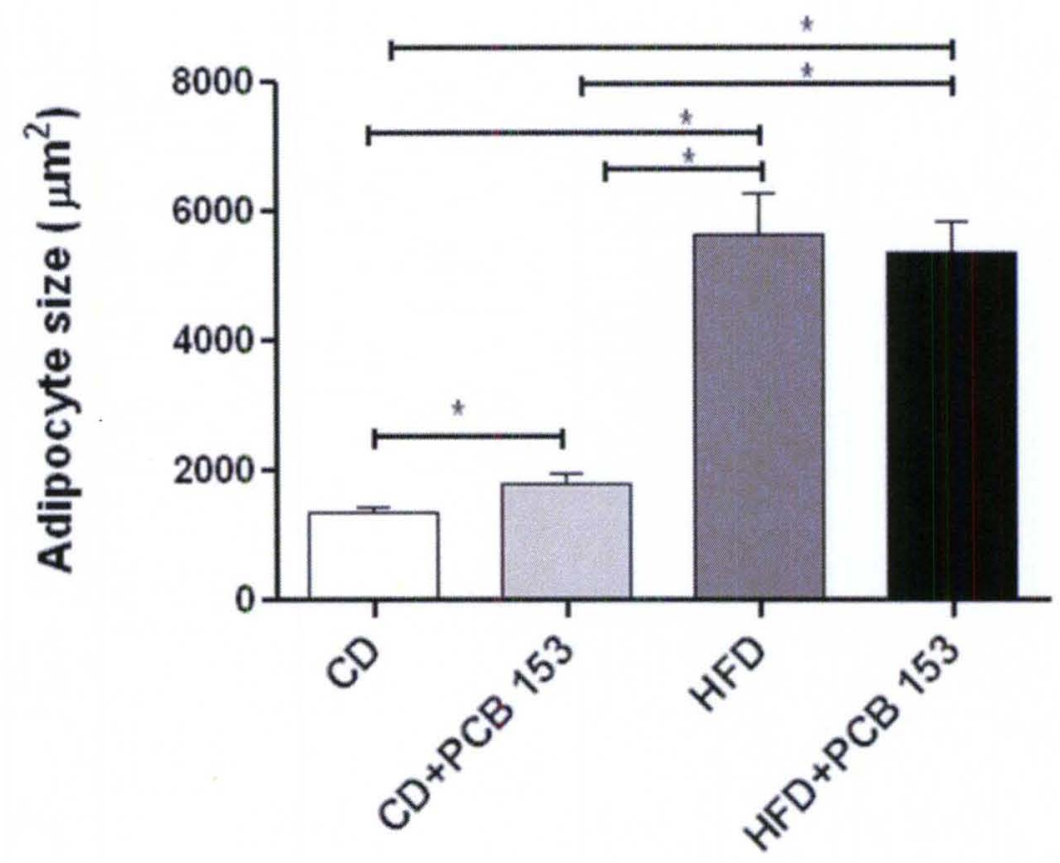

Figure 4. HFD increased adipocyte cell size $\left(\mu \mathrm{m}^{2}\right)$ and this was unaffected by PCB 153.

Adipocyte area was measured and the average cell size of $>100$ cells for each of the groups $(n=10)$ was calculated. The adipocyte cell size $\left(\mu m^{2}\right)$ was increased in mice fed with HFD and this effect was not changed with PCB 153 coadministration. Data are expressed as mean \pm SEM. * $P<0.05$. CD-control diet, HFD-high fat diet, PCB-polychlorinated biphenyl. 
PCB 153 worsened NAFLD in mice fed high fat diet, but had no hepatic effects in mice fed control diet.

CD-fed mice did not develop significant steatosis by histology (Oil Red O and H\&E stains-Figure 5 \& 6) with either vehicle control or PCB 153. In contrast, HFD increased steatosis which appeared to be even greater with PCB 153 coexposure (vs. vehicle).

Hepatic necro-inflammation was evaluated by histology (H\&E), plasma aminotransferase activity, and hepatic TNFa message (RT-PCR). Qualitatively, significant necro-inflammation was not observed histologically in either group (Figure 6). Mean plasma AST activity levels were slightly, but significantly higher with HFD+PCB $153(54.13 \pm 4.65 \mathrm{U} / \mathrm{L})$ vs. either CD+vehicle $(37.09 \pm 1.99 \mathrm{U} / \mathrm{L}, \mathrm{p}$ $<0.05)$ or $\mathrm{CD}+\mathrm{PCB} 153(37.68 \pm 1.17 \mathrm{U} / \mathrm{L}, \mathrm{p}<0.05)$ (Figure 7). The mean AST level in the HFD+vehicle group $(49.85 \pm 4.52 \mathrm{U} / \mathrm{L})$ was significantly different $v s$. CD+vehicle group $(p<0.05)$ but not vs. CD+PCB 153. Mean plasma ALT activity levels were not significantly different between groups (Figure 8). Hepatic TNFa message was measured by RT PCR and normalized to GAPDH. Mean TNF $\alpha$ message levels were not significantly different between groups: $C D+$ vehicle (100 $\pm 24.03)$; CD+PCB 153 (106.90 \pm 40.06); HFD+vehicle (285.57 \pm 109.73$)$; HFD+PCB $153(60.47 \pm 16.81)$. Hepatic fibrosis was evaluated by Sirius red stain. As no qualitative differences were observed between treatment groups (data not shown), quantitative studies were not performed. 
Hepatic triglycerides and cholesterol were quantitated biochemically. In CD-fed mice, mean hepatic triglycerides were not significantly different between vehicle $(7.29 \pm 1.20 \mu \mathrm{g} / \mathrm{mg}$ tissue $)$ and PCB 153 treatment $(4.63 \pm 1.85 \mu \mathrm{g} / \mathrm{mg}$ tissue) (Figure 9). Likewise, hepatic cholesterol levels were not significantly different between vehicle $(2.75 \pm 0.39 \mu \mathrm{g} / \mathrm{mg}$ tissue $)$ and PCB $153(3.15 \pm 0.93$ $\mu \mathrm{g} / \mathrm{mg}$ tissue) treated mice fed with CD (Figure 10). In contrast, HFD-fed mice had significantly higher mean hepatic triglyceride levels with PCB 153 (56.37 \pm $14.36 \mu \mathrm{g} / \mathrm{mg}$ tissue) $v s$. vehicle control $(17 \pm 6.35 \mu \mathrm{g} / \mathrm{mg}$ tissue, $\mathrm{p}<0.05)$. Indeed, HFD+PCB 153 co-exposure resulting in significantly higher hepatic triglycerides than all other treatments. Hepatic cholesterol levels were not significantly different between HFD+vehicle (5.08 $\pm 1.49 \mu \mathrm{g} / \mathrm{mg}$ tissue) $v s$. HFD+PCB 153 $(9.26 \pm 2.21 \mu \mathrm{g} / \mathrm{mg}$ tissue). However, mean hepatic cholesterol levels were significantly higher with HFD+PCB 153 vs. both CD+vehicle or CD+PCB 153 (Figure 10).

In summary, the combination of PCB 153 and HFD dramatically increased steatosis, marginally worsened necro-inflammation, but had no effect on fibrosis. PCB 153 had no effect on these parameters in mice fed CD. 


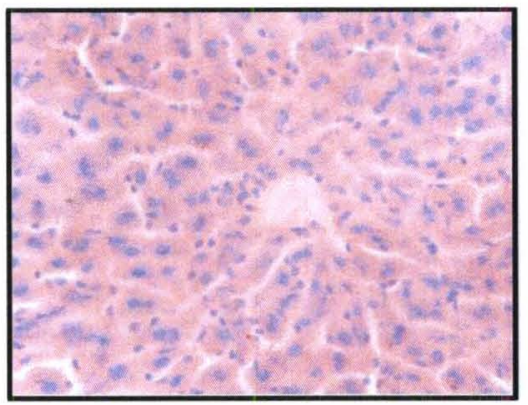

CD

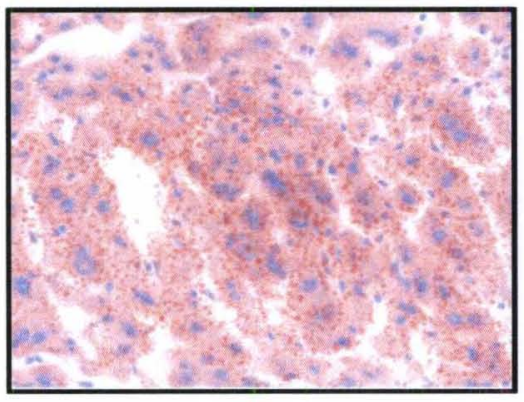

HFD

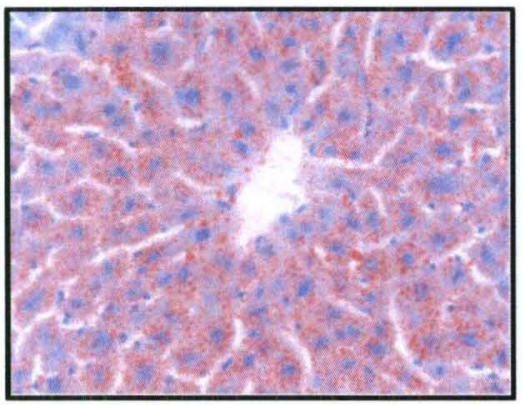

CD+PCB 153

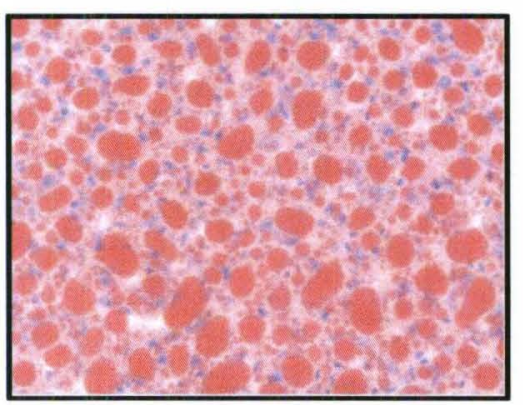

HFD+PCB 153

Figure 5. Oil Red O staining of liver tissue.

Oil Red O staining of hepatic sections established the occurrence of microvesicular steatosis in the HFD+PCB 153 mice. There was no evidence of microvesicular steatosis in mice fed CD without or with PCB 153 co-administration. CD-control diet, HFD-high fat diet, PCB-polychlorinated biphenyl. 


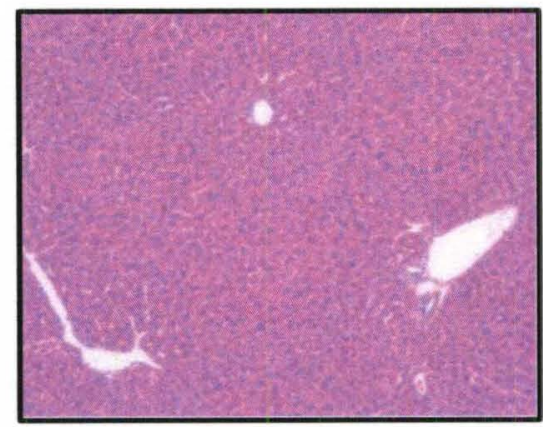

CD

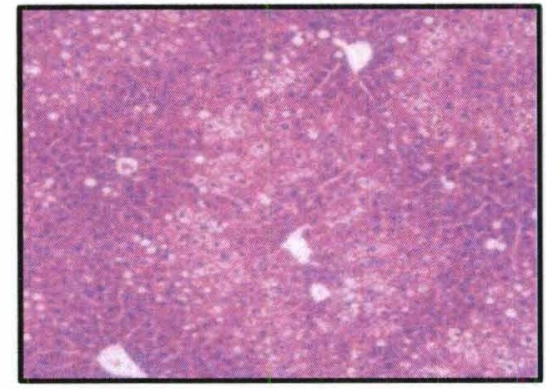

HFD

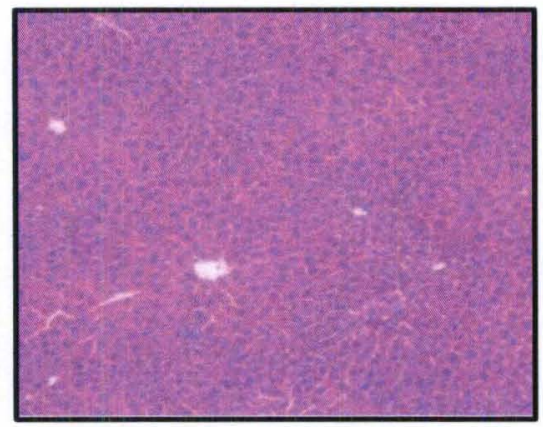

CD+PCB 153

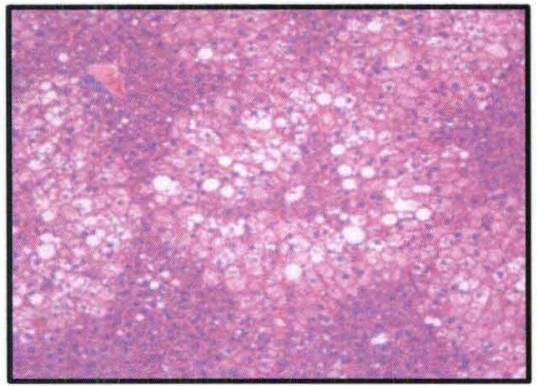

HFD+ PCB 153

Figure 6. H\&E staining of liver tissue.

H\&E staining of hepatic sections established the occurrence of macro-vesicular steatosis in the HFD+PCB 153 mice. Macro-vesicular steatosis was not observed in mice fed CD without or with PCB 153 co-administration. CD-control diet, HFDhigh fat diet, PCB-polychlorinated biphenyl. 


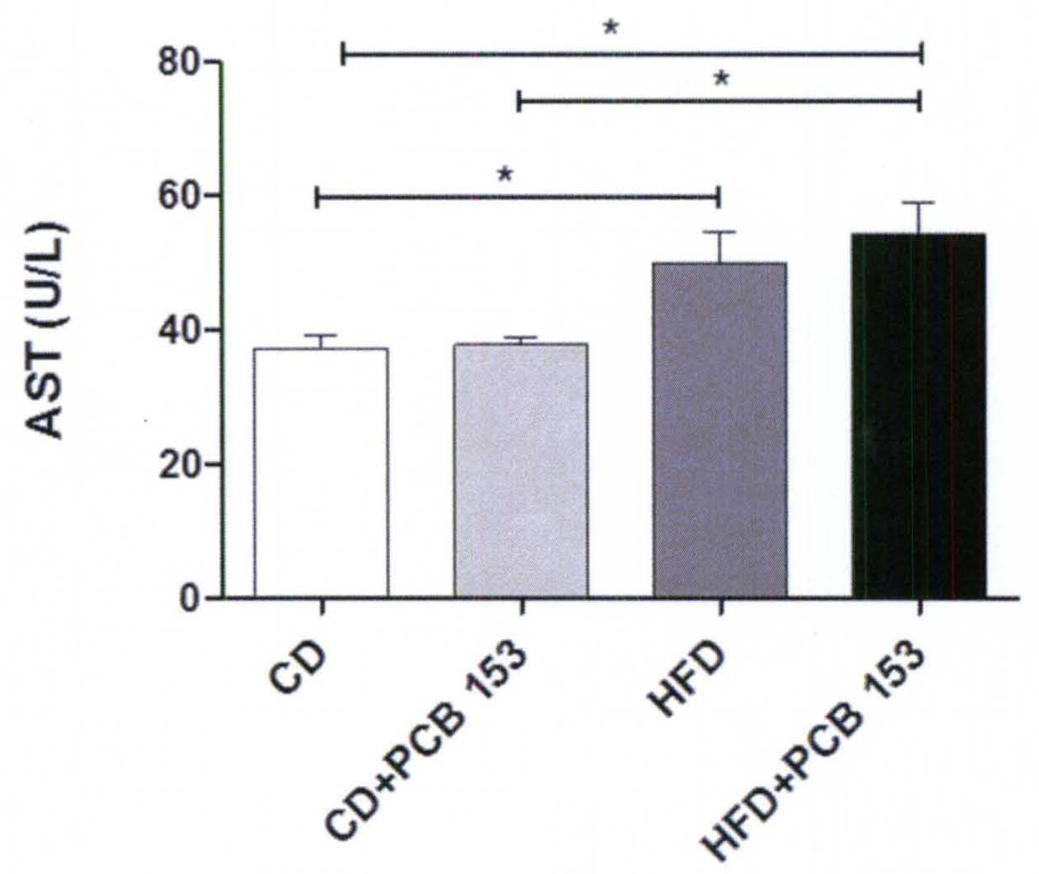

Figure 7. Effects of HFD and PCB 153 on plasma AST levels.

Plasma AST levels $(U / L)$ were measured $(n=10)$ using Cobas Mira Plus automated chemical analyzer. The AST levels were significantly higher for the HFD+PCB 153 group as compared to CD or CD+PCB 153. Data are expressed as mean \pm SEM. * $P<0.05$. CD-control diet, HFD-high fat diet, PCBpolychlorinated biphenyl, AST-aspartate transaminase. 


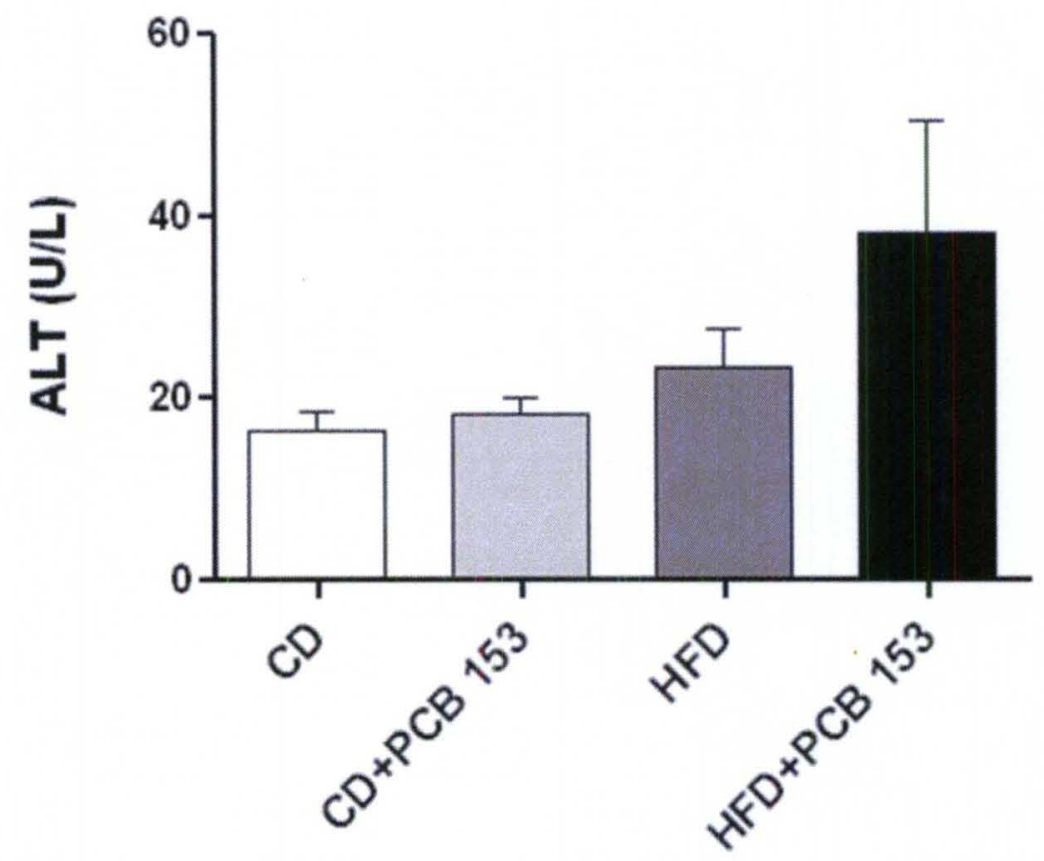

Figure 8. Effects of HFD and PCB 153 on plasma ALT levels.

Plasma ALT levels $(U / L)$ were measured $(n=10)$ using Cobas Mira Plus automated chemical analyzer. No significant change was observed in any group.

Data are expressed as mean \pm SEM. ${ }^{*} P<0.05$. CD-control diet, HFD-high fat diet, PCB-polychlorinated biphenyl, ALT-alanine transaminase. 


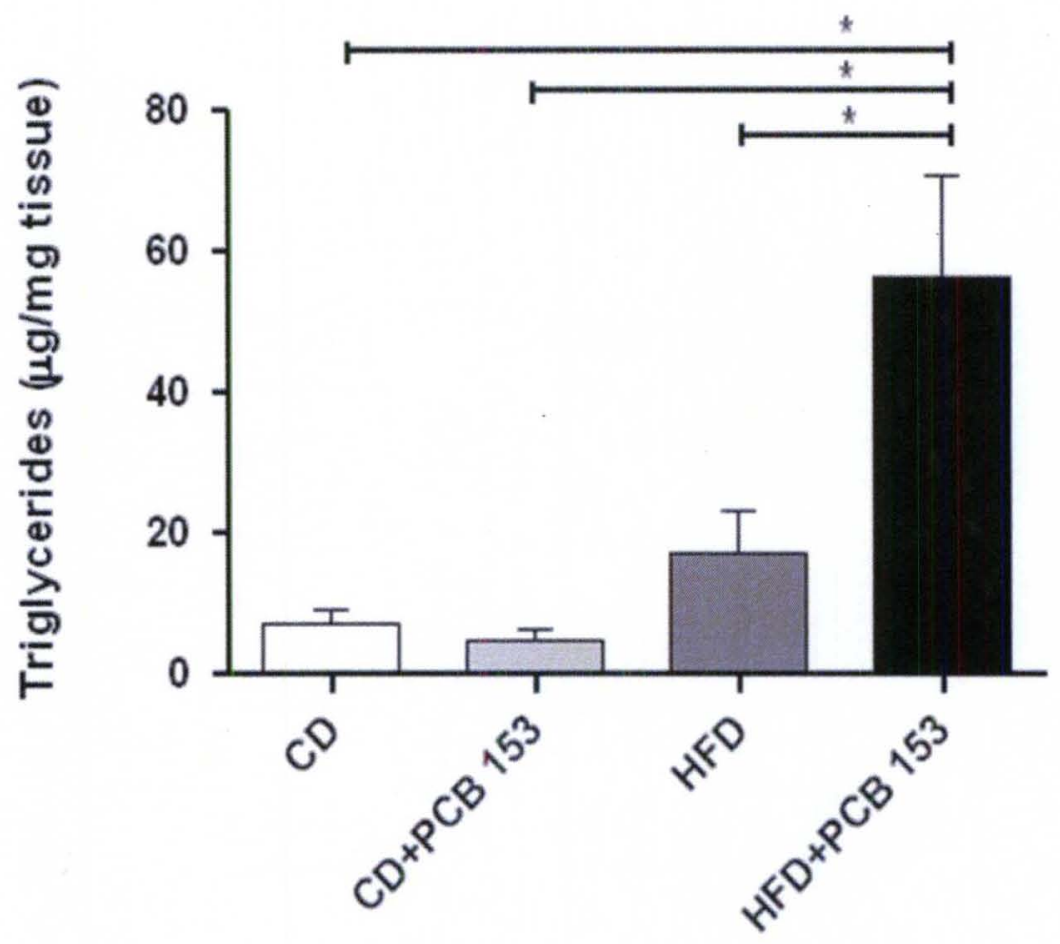

Figure 9. Effects of HFD and PCB 153 on hepatic triglyceride levels.

Hepatic levels of triglycerides were quantified ( $\mu \mathrm{g} / \mathrm{mg}$ tissue) in mice $(n=5)$ fed with control or high fat diet with or without PCB 153. PCB 153 increased hepatic triglyceride levels in mice fed a HFD. Data are expressed as mean \pm SEM. * $P$ $<0.05$. CD-control diet, HFD-high fat diet, PCB-polychlorinated biphenyl. 


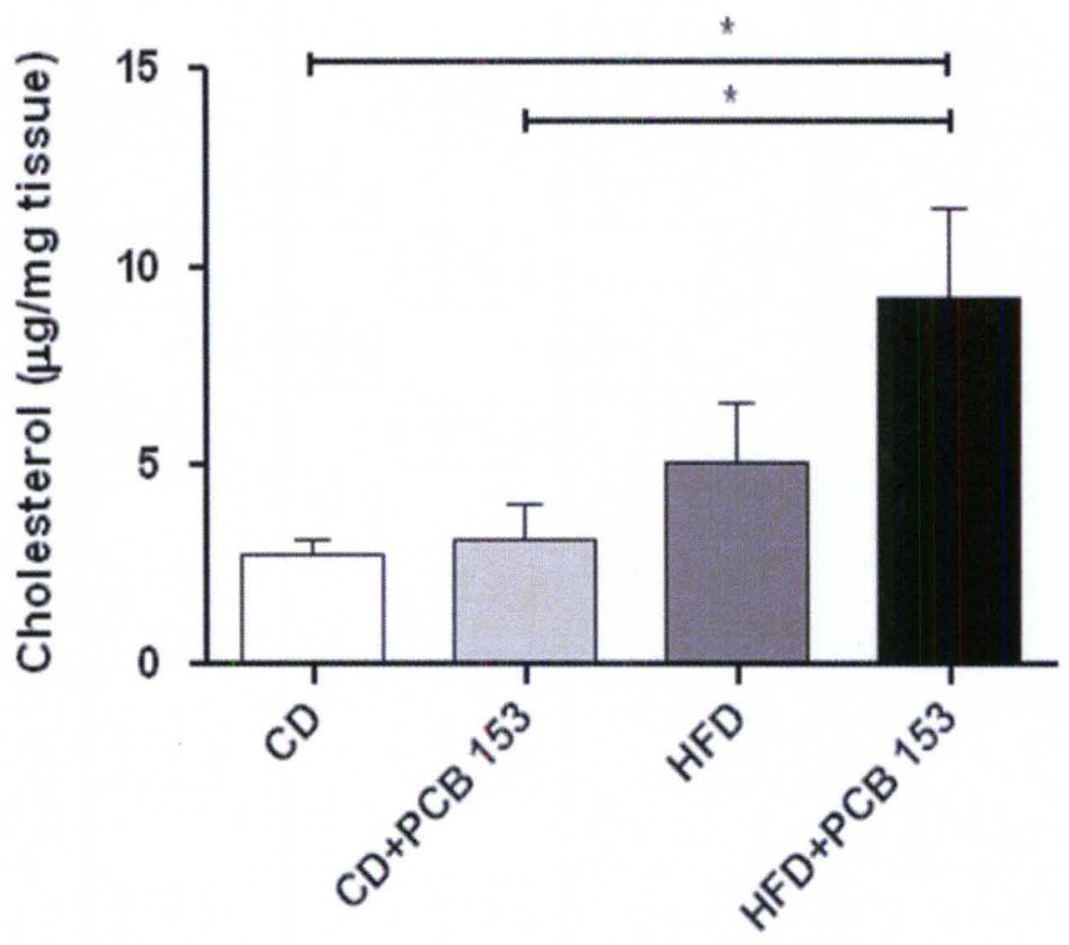

Figure 10. Effects of HFD and PCB 153 on hepatic cholesterol levels.

Hepatic levels of cholesterol were quantified ( $\mu \mathrm{g} / \mathrm{mg}$ tissue) in mice $(n=5)$ fed with control or high fat diet with or without PCB 153. PCB 153 increased hepatic cholesterol levels in mice fed a HFD. Data are expressed as mean \pm SEM. * $P$ $<0.05$. CD-control diet, HFD-high fat diet, PCB-polychlorinated biphenyl. 
Insulin resistance, glucose regulation and serum lipoproteins: Effects of HFD and PCB 153.

In order to evaluate insulin resistance which may complicate obesity, HOMA-IR was determined and GTT was performed. As observed by HOMA-IR (Figure 11) HFD+vehicle $(3.80 \pm 0.48)$ was associated with insulin resistance but this effect was not augmented by HFD+PCB $153(3.83 \pm 0.62)$. However, HOMAIR levels were significantly higher in HFD+vehicle vs. CD+vehicle $(1.26 \pm 0.17)$ and $C D+P C B 153(1.30 \pm 0.35, p<0.05)$. Likewise, HOMA-IR levels were significantly higher in HFD+PCB 153 vs. CD+vehicle and CD+PCB 153 ( $p$ $<0.05)$. GTT was performed and compared to CD; PCB 153 had no additive effect to dietary manipulation alone (Figure 13). However, in CD-fed mice, PCB 153 administration was associated with lower fasting blood glucose levels (170.40 $\pm 4.57 \mathrm{mg} / \mathrm{dL}$ for CD+vehicle vs. $147.10 \pm 5.92 \mathrm{mg} / \mathrm{dL} C D+P C B ~ 153$, $p=0.006$ ) (Figure 12). Furthermore, HFD+vehicle and HFD+PCB 153 significantly increased the glucose area under the curve (AUC) (Figure 13 \& 14) $(p<0.05)$ which was obtained from GTT.

The plasma levels of total cholesterol, triglycerides, high density lipoproteins (HDL) and low density lipoproteins (LDL) were measured in all animal groups (Table 2). No significant differences in total cholesterol, triglycerides, LDL and HDL were observed in mice administered CD+vehicle vs. CD+PCB 153. Likewise mean lipid levels were unchanged in HFD+vehicle vs. 
HFD+PCB 153. However, total cholesterol, LDL, and HDL were significantly higher for HFD+PCB 153 vs. CD+PCB 153 ( $p<0.05$ - Table 2).

In summary, HFD was associated with insulin resistance and serum hypercholesterolemia, but PCB 153 had no additional effect on these parameters. 


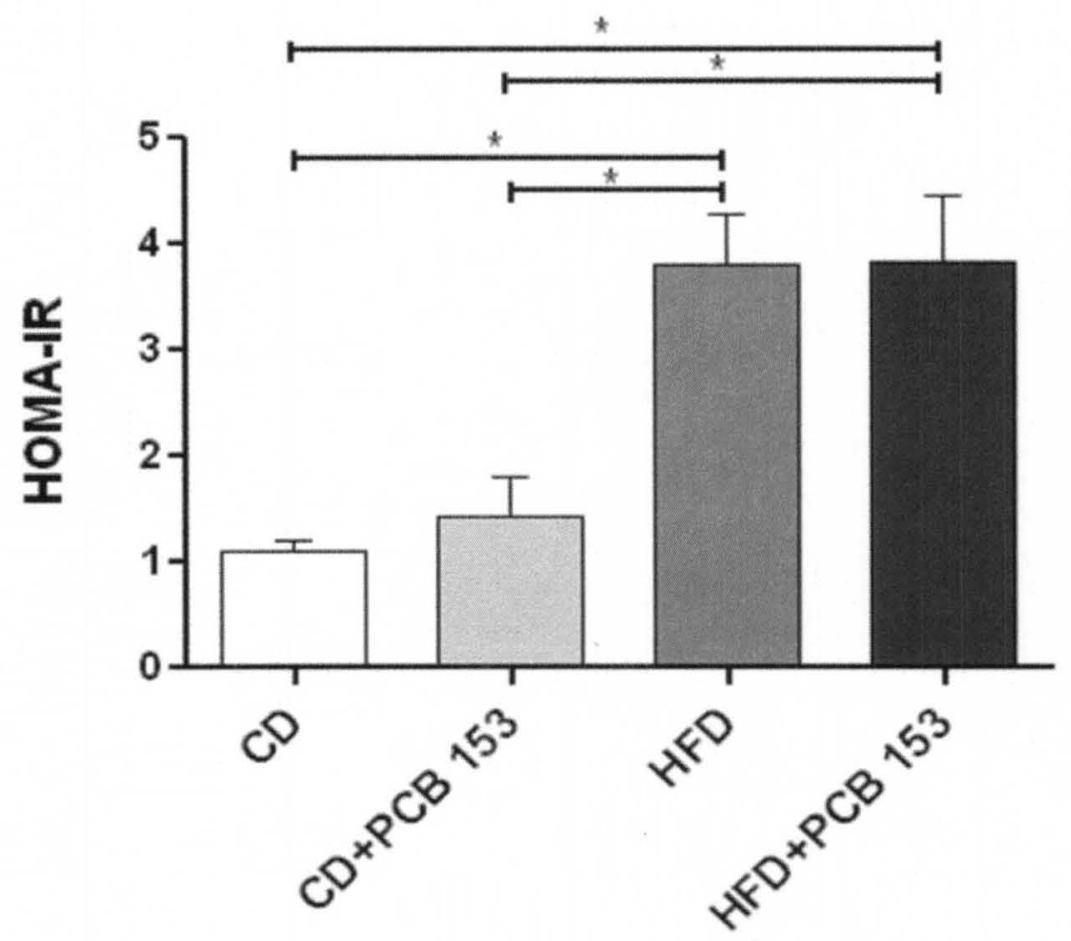

Figure 11. HFD increased insulin resistance and this was unaffected by РСВ 153 co-exposure.

HOMA-IR was caluclated from fasting blood glucose and insulin levels for all four groups of animals $(n=10)$. HFD and HFD+PCB 153 groups showed higher levels of HOMA-IR, indicative of insulin resistance, as compared to $C D$ and $C D+P C B$ 153 groups. Data are expressed as mean \pm SEM. ${ }^{*} P<0.05$. CD-control diet, HFD-high fat diet, PCB-polychlorinated biphenyl. 


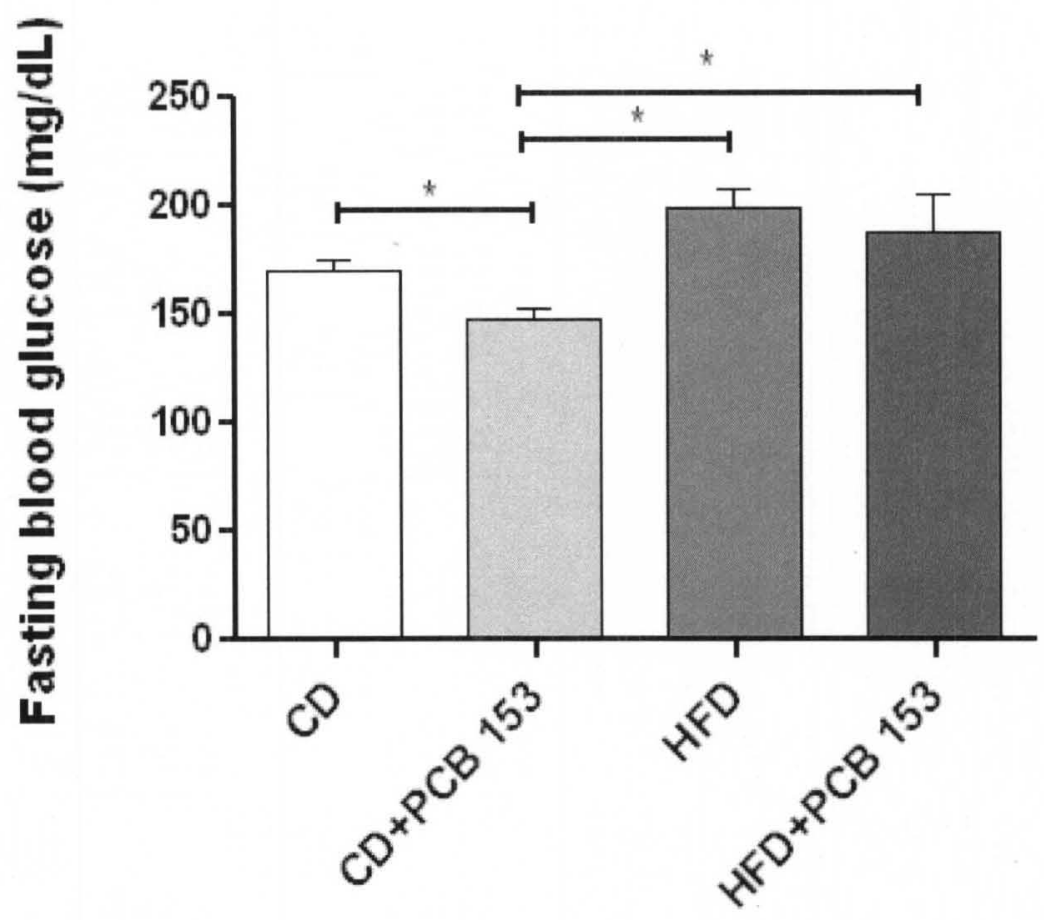

Figure 12. Fasting blood glucose levels.

Fasting blood glucose levels (mg/dL) were measured for all animals. HFD and HFD+PCB 153 showed higher fasting blood glucose levels when compared to CD group. CD+PCB 153 showed significantly lower fasting blood glucose levels when compared to $C D$ alone. Data are expressed as mean \pm SEM. * $P<0.05$. CD-control diet, HFD-high fat diet, PCB-polychlorinated biphenyl. 


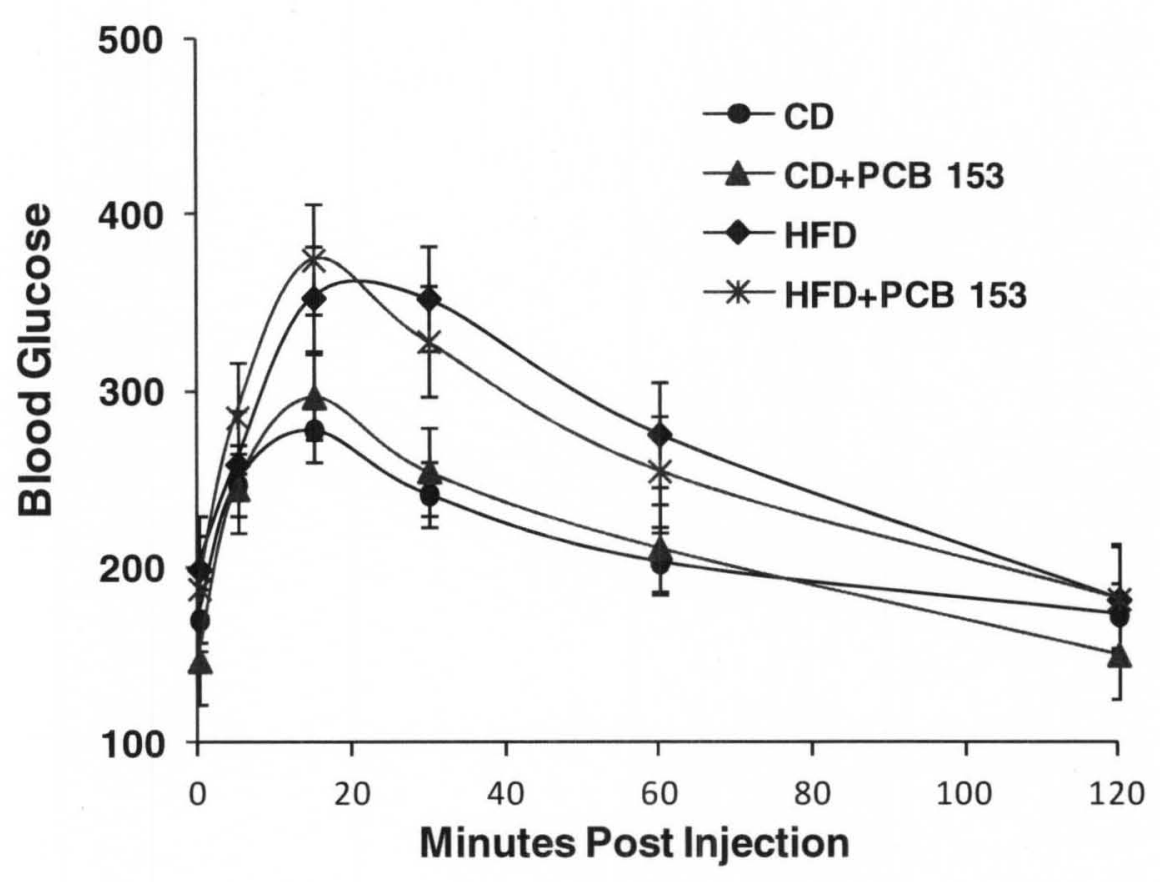

Figure 13. Glucose tolerance test (GTT).

Glucose tolerance test was performed and blood glucose levels were measured for mice $(n=10)$ fed with a control or high fat diet, with or without PCB 153. High fat diet increased glucose tolerance and this was unaffected by PCB 153. CDcontrol diet, HFD-high fat diet, PCB-polychlorinated biphenyl. 


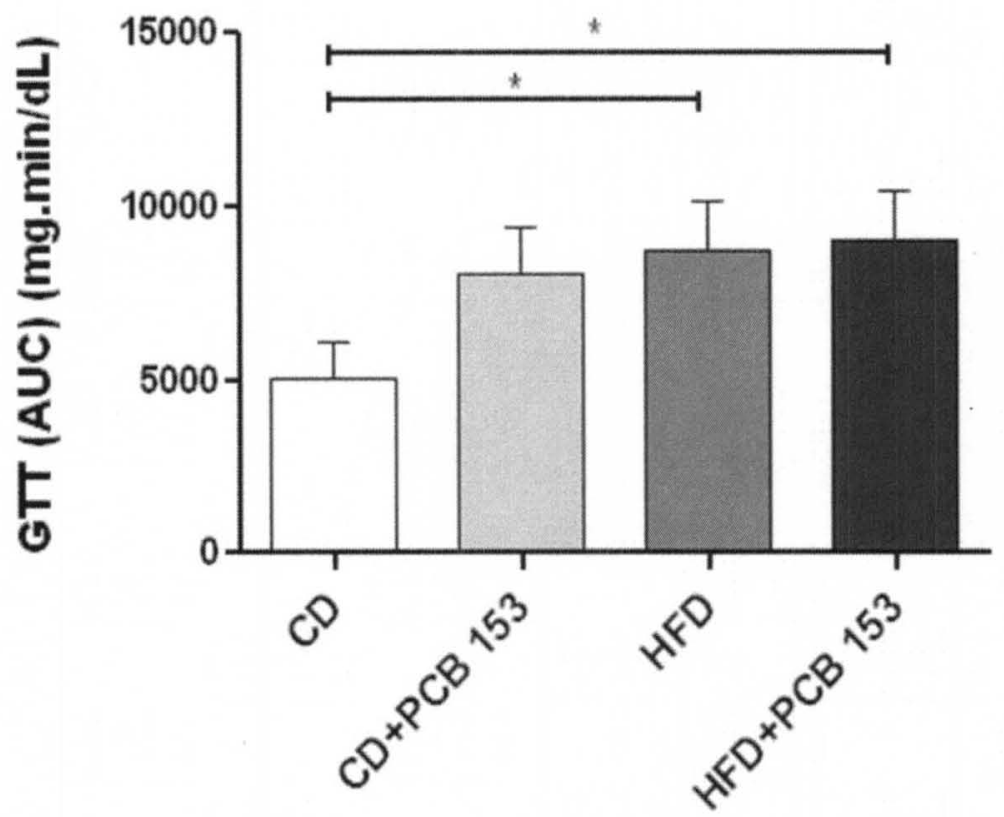

Figure 14. Area under the curve calculated from GTT.

Area under the curve was calculated from the glucose tolerance test readings. HFD and HFD+PCB 153 groups showed higher AUC levels than CD or CD+PCB 153 groups. Data are expressed as mean \pm SEM. * $P<0.05$. CD-control diet, HFD-high fat diet, PCB-polychlorinated biphenyl. 


\begin{tabular}{lcccc}
\hline & CD & CD+PCB 153 & HFD & HFD+PCB 153 \\
\hline Cholesterol & $70.01 \pm 10.29$ & $69.88 \pm 16.50$ & $136.78 \pm$ & $141.52 \pm$ \\
& & & $37.65^{\mathrm{a}}$ & $27.49^{\mathrm{a}}$ \\
Triglycerides & $33.85 \pm 12.95$ & $38.63 \pm 19.86$ & $23.39 \pm 4.17$ & $34.17 \pm 27.11$ \\
HDL & $54.73 \pm 5.07$ & $58.85 \pm 10.92$ & $111.01 \pm$ & $113.80 \pm$ \\
& & & $31.02^{\mathrm{a}}$ & $17.69^{\mathrm{a}}$ \\
LDL & $14.03 \pm 2.39$ & $14.29 \pm 4.07$ & $33.74 \pm 9.67^{\mathrm{a}}$ & $31.25 \pm 8.79^{\mathrm{a}}$ \\
\hline
\end{tabular}

Table 2. Plasma levels of total cholesterol, triglycerides, high density and low density lipoproteins

${ }^{a} p<0.05$ compared with mice fed CD alone or co-administered with PCB 153.

Values are mean \pm SEM $(\mathrm{mg} / \mathrm{dL})$. CD-control diet, HFD-high fat diet, PCB-

polychlorinated biphenyl, HDL-high density liporoteins, LDL-low density lipoproteins. 


\section{DISCUSSION}

The most striking result of this study was the synergistic interaction between PCB 153 and HFD resulting in dramatically increased obesity. Historically, exposures to PCBs, and the related molecule TCDD, have been associated with wasting syndrome, although hypercaloric diets were not utilized $(34,35)$. Consistent with these historical observations, a decrease in \% body weight gain was observed in the CD-fed mice administered with PCB 153 vs. vehicle control. However, recent epidemiological studies, which did not control for diet, revealed an association between serum levels of specific PCB congeners and human obesity $(12,13)$. Likewise, an increase in \% body weight gain corresponding with qualitatively increased visceral fat was observed in mice with PCB 153+HFD co-exposure vs. HFD alone. These seemingly paradoxical findings could potentially be explained by (i) the fact that PCB 153 is not an AhR agonist as are the PCBs used in most prior rodent studies, (ii) AhR has dramatically different activities in rodents and humans (36), and (iii) unlike the rodent studies, in the epidemiologic studies, humans are simultaneously being exposed to hypercaloric diets. Although we can retrospectively rationalize our findings, they were nonetheless unexpected. Therefore, metabolic cages were not used and adiposity was not precisely quantitated. We were, however, able to quantitate adipocyte size which showed that PCB 153 had no effect on adipocyte size over HFD alone. 
Despite changes in obesity, PCB 153 was not associated with increased insulin resistance (HOMA-IR). However some alterations were observed in glucose metabolism. There was a non-significant trend towards higher AUC levels (glucose tolerance test) with significantly lower fasting blood glucose levels in CD-fed mice co-administered with PCB 153 which theoretically could be explained by CAR activation (37). Notably, PCB 153 was associated with human diabetes in adult NHANES (15), indicating that other factors may have driven insulin resistance. A more recent prospective human study determined that higher baseline levels of PCBs with greater than 7 chlorine atoms (and not PCB 153 that has six chlorines) were associated with the subsequent development of greater BMI, insulin resistance, and triglycerides (38). Therefore, it appears that the effects of PCBs on obesity/metabolic syndrome may be congener-dependent and depend on affinity for the AhR and degree of chlorination.

Concordant with the increase in obesity, PCB 153 worsened NAFLD in HFD mice. Steatosis was dramatically increased by the combination of PCB $153+$ HFD. In contrast to steatosis, which increased considerably, hepatic necroinflammation was only minimally increased by HFD+PCB 153 . While mean plasma AST activity was significantly increased in this group, no significant changes were observed in ALT, necro-inflammation by histology, hepatic TNFa message levels, or plasma levels of TNFa, IL-6, or IL-10. Previous epidemiological study from our laboratory found a dose-dependent association between plasma PCB levels and elevated ALT in adult NHANES subjects (4). 
However, weaker associations were also noted between PCBs and elevated AST levels. PCB 153 was not associated with hepatic inflammation, although preliminary in vitro studies from our laboratory showed that PCB exposures increased TNFa production from Raw 264.7 cells, a murine macrophage cell line (39). However, these differences could be PCB congener/dose specific or related to differences between in vitro vs. in vivo systems. 


\section{CHAPTER 3}

\section{MECHANISMS BY WHICH PCB 153 PROMOTE OBESITY INTRODUCTION}

The characteristics of NAFLD/obesity include but are not limited to hepatic steatosis, insulin resistance and increased serum cholesterol. Adipokine dysregulation is another probable factor that drives NAFLD towards metabolic syndrome. Furthermore, in our studies, there was marked evidence for the occurrence of hepatic steatosis in mice fed a HFD and co-exposed to PCB 153. Deposition of fat in the liver can occur through different mechanisms such as increased synthesis and decreased catabolism of fat in liver (40) or increased import of fat to liver and decreased export to other tissues (24). We therefore measured the serum levels of adipokines such as adiponectin, leptin, resistin and tissue plasminogen activator inhibitor (t-PAI 1) as well as cytokines.

To further understand the mechanism that led to steatosis, mRNA expression of enzymes involved in fatty acid metabolism was examined. These

enzymes included fatty acid synthase (FAS) for fatty acid synthesis, PPAR $\alpha$ and carnitine palmitoyl transferase $1 \mathrm{~A}$ and 2 (CPT1A and 2) for fatty acid oxidation. The mRNA expression of fatty acid binding protein 1 (FABP1), utilized for fatty acid transport, was also examined. 
Another aspect that we studied is related to the slight increase in adiponectin levels in the plasma as compared to the high fold-change observed with leptin in the HFD+PCB 153 group. We hypothesize that the decreased adiponectin:leptin ratio seen in this group may be due to endoplasmic reticulum (ER) stress brought upon by PCB exposure in high fat-fed mice.

ER stress refers to the phenomenon when the protein load in the ER exceeds the ER folding capacity; hence, also known as unfolded protein response (UPR) (41). Synthesis, folding and maturation of secreted and transmembrane proteins occur in the endoplasmic reticulum (ER). ER is also the site of lipid biosynthesis and calcium $\left(\mathrm{Ca}^{2+}\right)$ storage. Causes of ER stress are diverse and range from $\mathrm{Ca}^{2+}$ to cholesterol accumulation and phospholipid depletion (42).

One of the defining features in ER stress is the upregulation of the CAATenhancer binding protein (C/EBP) homologous protein 10 (CHOP 10), also known as DNA damage-inducible transcript 3 (DDIT 3) (43). CHOP-10 belongs to the family of bZIP C/EBP like transcription factors and has been implicated in ER stress, oxidative stress and nutrient deprivation $(44,45)$. UPR is an adaptive mechanism initiated by the cell in response to demand for protein folding. The presence of misfolded proteins in ER attracts immunoglobulin heavy chain binding protein $(\mathrm{BiP})$; BiP's principal role is to bind to ER stress transducers in their inactive form towards it (41). Dissociation of the chaperone protein BiP from the ER stress transducer protein kinase RNA-activated (PKR)-like ER kinase 
(PERK) leads to phosphorylation of the translation initiation factor 2 (elF2 $\alpha$ )

(Figure 15). Phosphorylation of elF2 $\alpha$ leads to nuclear translocation of activating nuclear transcription 4 (ATF4) which induces CHOP $10(46,47)$. CHOP 10 plays a functional role in apoptosis, diabetes mellitus and adipocyte differentiation (45, $48,49)$. 


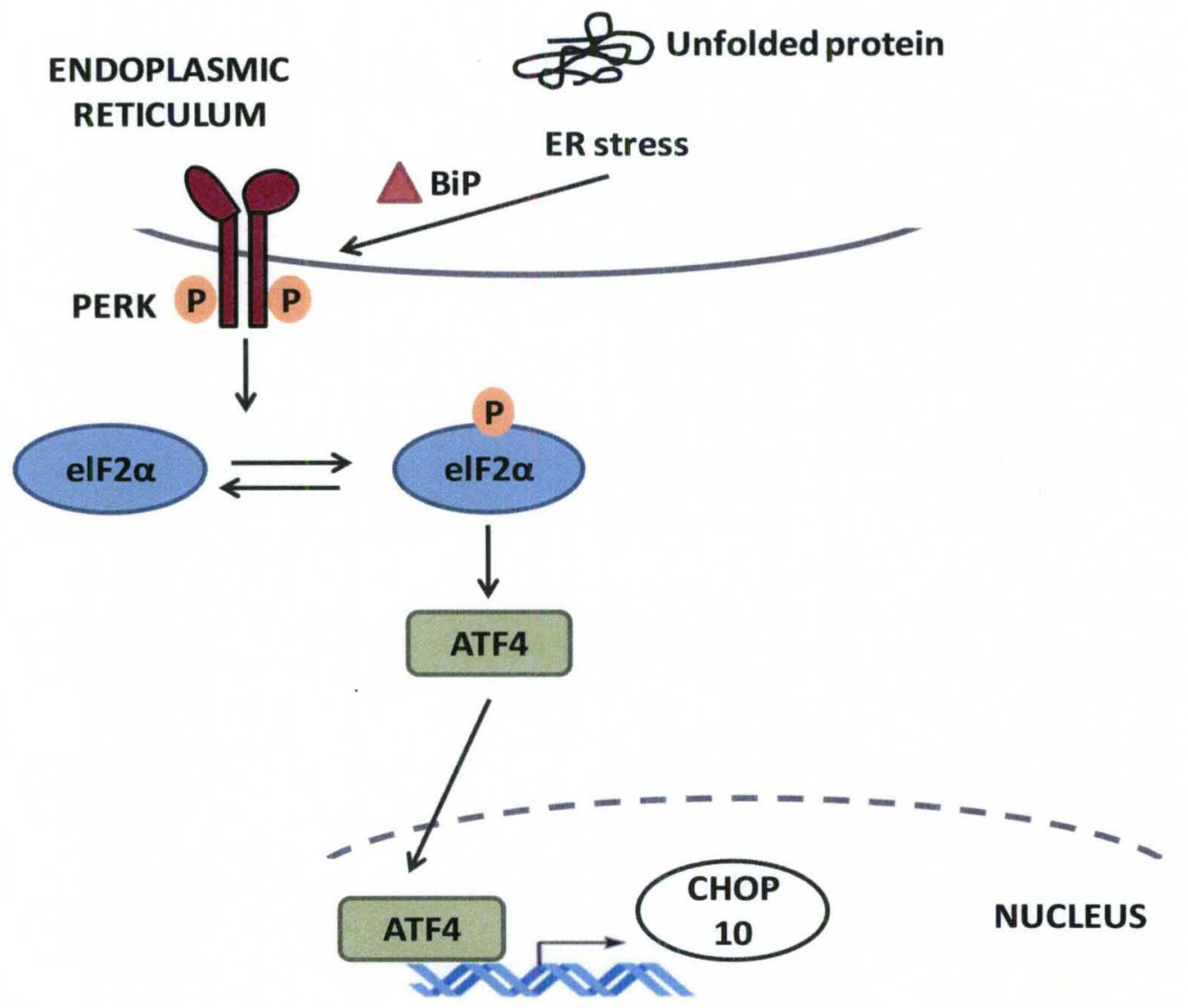

Figure 15. Upregulation of CHOP 10 in endoplasmic reticulum (ER) stress. 
Growth and differentiation of preadipocytes involve a complex sequence of transcription factors that are interdependent and can either stimulate or inhibit adipocyte differentiation, eventually affecting adipocyte genes and adipocyte secretory hormone levels.

Adipocytes or fat cells arise from fibroblasts that require growth arrest and terminal differentiation to become functional and matured adipocytes. Growth arrest is controlled by CAAT-enhancer binding protein alpha (C/EBPa) and peroxisome proliferator-activated receptor gamma (PPARY), transcription factors that transactivate adipocyte-specific genes (48). C/EBPa increases p21 (cyclindependent kinase inhibitor) levels and has anti-mitotic activity (50) while PPARY decreases the transcriptional activity of E2F/DP-1 complex which controls DNA synthesis (51). PPARy attains maximal level of expression in matured adipocytes. C/EBP $\beta$, a transcriptional activator of C/EBPa and C/EBPס, precedes $\mathrm{C} / \mathrm{EBPa}$ expression. CHOP 10 is expressed in growth arrested preadipocytes and it transiently sequesters C/EBP $\beta$ by heterodimerization (52). C/EBP $\beta$ and C/EBPס co-expression is essential for PPARy expression (53), thus these transcription factors have temporal and spatial expressions that influence each other. Therefore, $\mathrm{CHOP} 10$ is a negative modulator of the C/EBP transcriptional activity and its upregulation leads to decreased C/EBP $\beta$ and C/EBPס levels, which subsequently repress C/EBPa and PPARy expression. Suggested PPARy target genes include adiponectin, lipoprotein lipase (LPL) and adipocyte protein 2 (aP2) or fatty acid binding protein 4 (FABP4) $(54,55)$. 


\section{MATERIALS AND METHODS}

Cytokines and adipokines measurement. Plasma cytokine and adipokine levels were measured using Milliplex Mouse Serum Cytokine and Adipokine Kits (Millipore Corp, Billerica, MA) on the Luminex IS 100 system (Luminex Corp, Austin, TX), as per the manufacturer's instructions.

Real time-PCR. Mouse liver and adipose tissue samples were homogenized and total RNA was extracted using the RNA-STAT 60 protocol (Tel-Test, Austin, TX). cDNA was synthesized from total RNA using the QuantiTect Reverse Transcription Kit (Qiagen, Valencia, CA). PCR was performed on the Applied Biosystems StepOnePlus Real-Time PCR Systems using the Taqman Universal PCR Master Mix (Life Technologies, Carlsbad, CA). Primer sequences (Taqman Gene Expression Assays) were obtained from Applied Biosystems (Foster City, $\mathrm{CA}$ ) and included the following (with the catalogue number): fatty acid synthase (FAS) (Mm00662319-m1), peroxisome proliferator-activated receptor alpha (PPARa) (Mm00440939-m1), carnitine palmitoyltransferase 1A (CPT1A) (Mm01231183-m1), carnitine palmitoyltransferase 2 (CPT2) (Mm00487205-m1), fatty acid binding protein 1 in liver (FABP1) (Mm00444340-m1), peroxisome proliferator-activated receptor gamma (PPARy) (Mm01184322-m1), CCAATenhancer-binding protein alpha (C/EBPa) (Mm00514283-s1), C/EBP homologous protein (CHOP 10) (Mm00492097-m1) and glyceraldehyde-3phosphate dehydrogenase (GAPDH) (4352932E). The levels of mRNA were normalized relative to the amount of GAPDH mRNA, and expression levels in 
mice fed CD and administered vehicle were set at $100 \%$. Gene expression levels were calculated according to the $2^{-\Delta \Delta \mathrm{Ct}}$ method (33).

Statistical Analysis. Statistical analyses were performed using GraphPad Prism version 5.01 for Windows and SigmaPlot 11.01. Data are expressed as mean \pm SEM. For 2 group comparison, an unpaired t-test was used, and multiple group data were compared using Two Way ANOVA followed by Tukey Test for posthoc all pairwise comparisons. $\mathrm{P}<0.05$ was considered statistically significant. 


\section{RESULTS}

PCB 153 altered plasma adipokine levels and expression although cytokine levels were unchanged.

HFD+PCB 153 increased leptin levels 56-fold vs. CD+vehcile $(p<0.05)$; and 25 -fold vs. CD+PCB $153(p<0.05)$ (Table 3). Three additional adipokines, adiponectin, resistin and tPAl-1, were also determined (Table 3). Compared to the large magnitude changes observed in plasma leptin levels, adiponectin levels were changed by a smaller amount. Adiponectin levels were higher in HFD+vehicle vs. $C D+$ vehicle and $C D+P C B$ 153. Likewise, adiponectin levels were higher in HFD+PCB 153 vs. both CD and CD+PCB 153. Resistin levels were significantly increased in HFD+PCB 153 vs. both HFD+vehicle and CD+vehicle $(p<0.05)$. Resistin levels were also significantly higher in HFD+vehicle vs. CD+vehicle $(p<0.05)$. No differences were noted between $\mathrm{CD}+\mathrm{PCB} 153$ vs. any other group. Similarly, mean plasma tPAl-1was significantly increased in HFD+PCB 153 vs. HFD+vehicle and vs. CD+vehicle ( $p$ <0.05). tPAI-1 levels were also significantly higher in HFD+vehicle vs. $C D+$ vehicle $(p<0.05)$. Plasma cytokines were measured and no change was observed in any of the animal groups for the pro-inflammatory cytokines, TNFa and IL-6, and the anti-inflammatory cytokine IL-10 (Table 3). Therefore, HFD+PCB 153 co-exposures led to significant changes in adipokines including the adiponectin, leptin, resistin, and tPAl-1; but did not affect cytokines including TNFa, IL-6, or IL-10. 


\begin{tabular}{|c|c|c|c|c|}
\hline Adipocytokines & CD & CD+PCB 153 & HFD & HFD+PCB 153 \\
\hline $\begin{array}{l}\text { Adiponectin } \\
(\mu \mathrm{g} / \mathrm{mL})\end{array}$ & $6.39 \pm 0.30$ & $6.57 \pm 0.38$ & $9.01 \pm 0.87^{\mathrm{a}}$ & $11.33 \pm 1.11^{\mathrm{a}}$ \\
\hline Leptin (pg/mL) & $\begin{array}{l}116.67 \pm \\
39.93\end{array}$ & $254.87 \pm 55.46$ & $\begin{array}{l}1279.28 \pm \\
360.11^{\mathrm{a}}\end{array}$ & $\begin{array}{l}6543.00 \pm \\
3550.89^{\mathrm{a}}\end{array}$ \\
\hline Resistin (ng/ mL) & $\begin{array}{l}742.02 \pm \\
134.44\end{array}$ & $838.02 \pm 246.11$ & $\begin{array}{l}941.09 \pm \\
310.87^{\mathrm{a}}\end{array}$ & $\begin{array}{l}1359.99 \pm \\
325.47^{\mathrm{a}, \mathrm{b}}\end{array}$ \\
\hline tPAl-1 (ng/mL) & $\begin{array}{l}152.47 \pm \\
71.32\end{array}$ & $218.05 \pm 91.06$ & $\begin{array}{l}363.80 \pm \\
142.82^{a}\end{array}$ & $\begin{array}{l}533.39 \pm \\
207.82^{a, b}\end{array}$ \\
\hline TNFa (pg/mL) & $0.52 \pm 0.49$ & $0.65 \pm 0.70$ & $0.99 \pm 1.44$ & $0.58 \pm 0.88$ \\
\hline IL-6 (pg/mL) & $3.80 \pm 2.62$ & $5.31 \pm 5.79$ & $12.69 \pm 13.07$ & $6.65 \pm 8.12$ \\
\hline IL-10 (pg/mL) & $1.54 \pm 0.33$ & $1.42 \pm 0.27$ & $3.55 \pm 3.03$ & $2.68 \pm 2.90$ \\
\hline
\end{tabular}

Table 3. Plasma cytokines' and adipokines' levels

${ }^{a} p<0.05$ compared with mice fed CD alone or co-administered with PCB 153. ${ }^{b}$ $p<0.05$ compared with mice fed HFD alone. Values are mean \pm SEM. CD-control diet, HFD-high fat diet, PCB-polychlorinated biphenyl, tPAl-1-tissue plasminogen activator inhibitor 1, TNFa-tumor necrosis factor alpha, IL-interleukin. 


\section{PCB 153 exposure altered gene expression of enzymes involved in hepatic}

\section{lipid metabolism.}

Real-time PCR was performed with total liver mRNA to analyze potential changes in expression of selected genes involved in fatty acid metabolism: FAS, PPARa, and CPT1A/2.

FAS expression was significantly increased in HFD+PCB $153(2530.53 \pm$ 1436.48) vs. CD+vehicle $(100 \pm 39.30, p<0.05)$ and vs. CD+PCB $153(422.05 \pm$ 169.58, $\mathrm{p}<0.05$ ) (Figure 16). Lower FAS expression was observed in HFD+vehicle (472.78 \pm 382.25$)$ vs. HFD+PCB 153 , and this was statistically significant $(p<0.05)$. Interestingly, HFD+vehicle showed significantly higher FAS expression when compared to $C D+$ vehicle group.

PPAR $\alpha$ expression was significantly decreased in HFD+PCB $153(19.09 \pm$ 7.89) vs. $\mathrm{CD}+\mathrm{PCB} 153(112.64 \pm 35.08, \mathrm{p}<0.05)$ and vs. CD+vehicle $(100 \pm$ 19.51, $\mathrm{p}<0.05$ ) (Figure 17). No significant differences were seen in PPARa expression in HFD+vehicle (40.98 \pm 13.17$)$ vs. any other group; although there was a non-significant trend towards higher PPAR $\alpha$ vs. HFD+PCB 153. CPT1A, a PPARa target gene and the rate limiting step in hepatic $\beta$ oxidation, was decreased in HFD+PCB $153(13.83 \pm 6.85)$ vs. CD+vehicle $(100 \pm 22.63, \mathrm{p}$ $<0.05)$ (Figure 18). Mean CPT2 expression was significantly decreased in HFD+PCB $153(14.58 \pm 5.53)$ vs. CD+vehicle $(100 \pm 15.15, p<0.05)$; and also in HFD+vehicle $(49.72 \pm 29.45)$ vs. CD+vehicle $(p<0.05)$ (Figure 19). CPT2 expression was numerically lower in HFD+PCB 153 than HFD+vehicle, but this 
observed trend was not statistically significant. FABP1 gene expression did not differ significantly between PCB-exposed and unexposed groups fed either a control or HFD.

Therefore, with HFD+PCB 153 co-exposure, the overall picture favored increased expression of genes implicated in fatty acid synthesis and decreased expression of genes involved in mitochondrial fatty acid $\beta$ oxidation. 


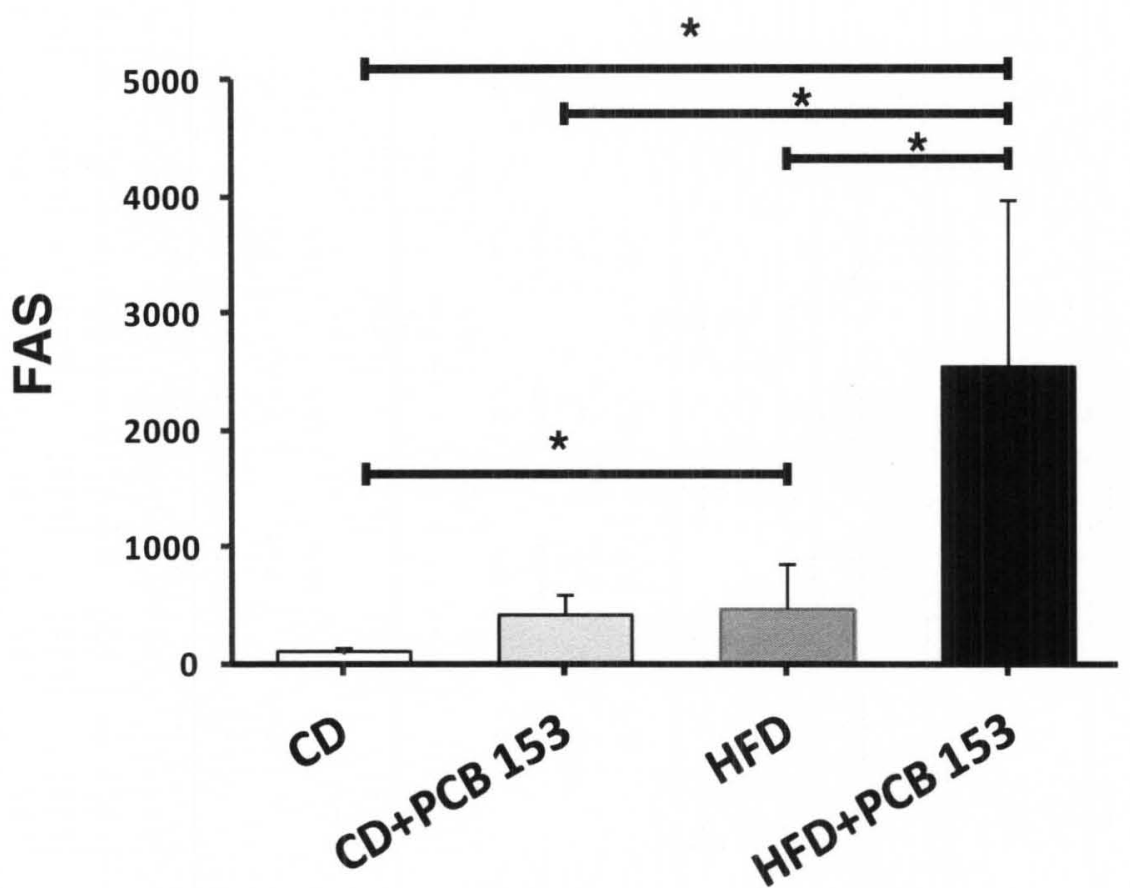

Figure 16. HFD and PCB exposure altered expression of FAS in liver.

Real-time PCR experiments showed the changes in hepatic mRNA expressions for fatty acid synthase (FAS) in mice liver caused by either PCB 153 exposure or HFD consumption or both as compared to gene expression in mice fed CD without or with PCB 153 exposure. All values were normalized to CD group, $(n=10)$. Data are expressed as mean \pm SEM. ${ }^{*} P<0.05$. CD-control diet, HFDhigh fat diet, PCB-polychlorinated biphenyl. 


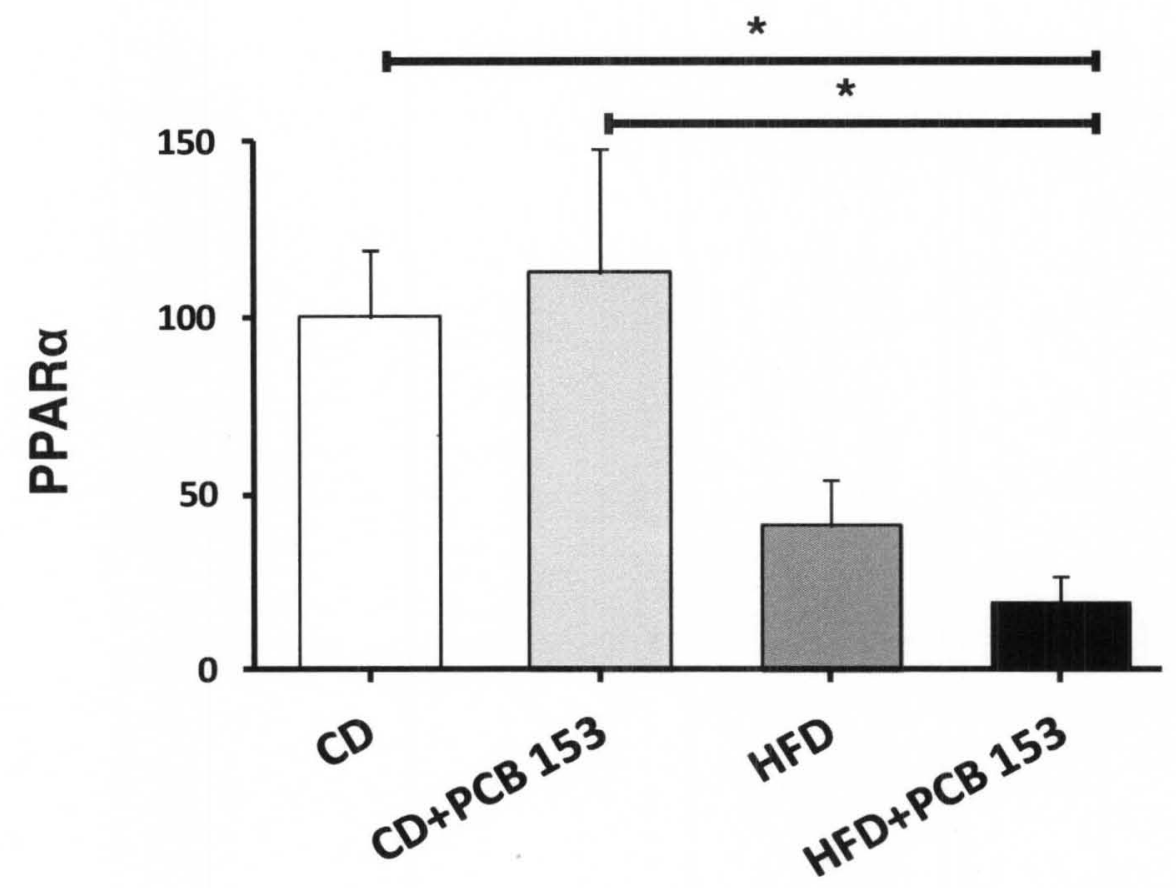

Figure 17. HFD and PCB exposure altered expression of PPARa in liver.

Real-time PCR experiments showed the changes in hepatic mRNA expressions for peroxisome proliferation activator alpha (PPAR $\alpha$ ) in mice liver caused by either PCB 153 exposure or HFD consumption or both as compared to gene expression in mice fed CD without or with PCB 153 exposure. All values were normalized to CD group, $(n=10)$. Data are expressed as mean \pm SEM. ${ }^{*} P<0.05$. CD-control diet, HFD-high fat diet, PCB-polychlorinated biphenyl. 


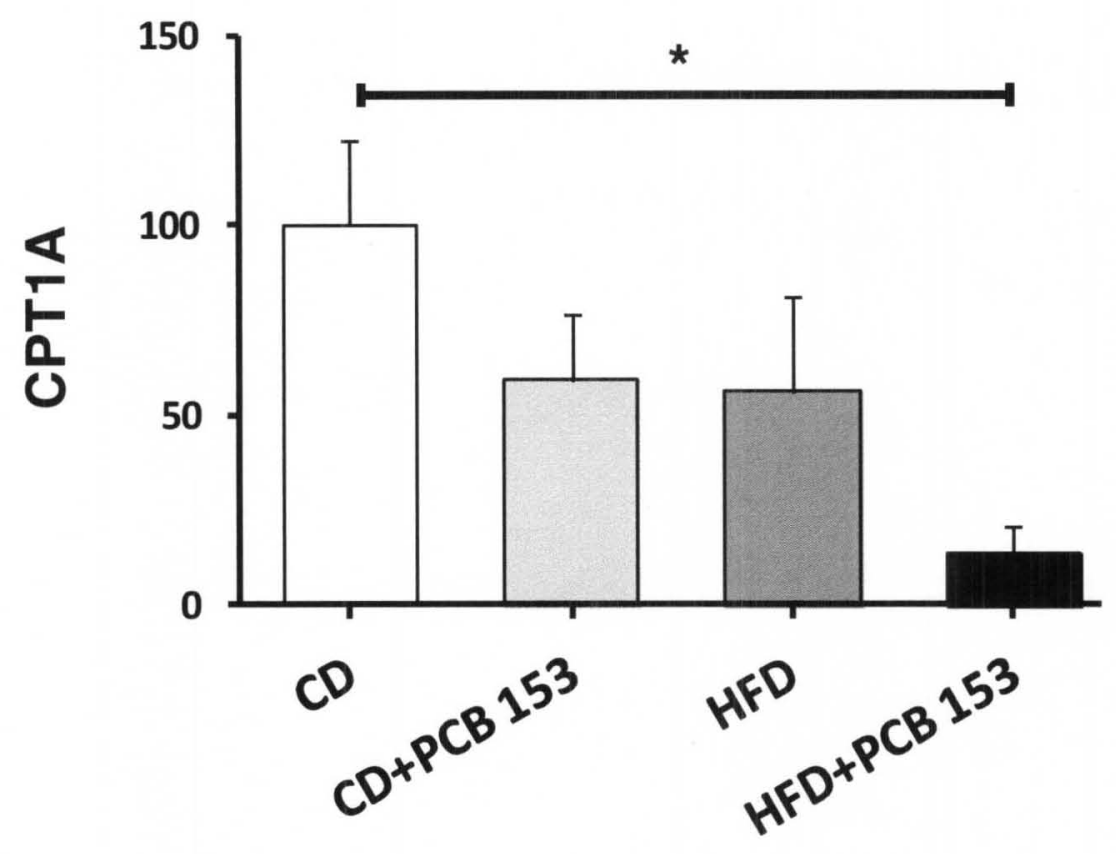

Figure 18. HFD and PCB exposure altered expression of CPT1A in liver.

Real-time PCR experiments showed the changes in hepatic mRNA expressions for carnitine palmitoyl transferase $1 \mathrm{~A}(\mathrm{CPT} 1 \mathrm{~A})$ in mice liver caused by either PCB 153 exposure or HFD consumption or both as compared to gene expression in mice fed CD without or with PCB 153 exposure. All values were normalized to CD group, $(n=10)$. Data are expressed as mean \pm SEM. ${ }^{*} P<0.05$. CD-control diet, HFD-high fat diet, PCB-polychlorinated biphenyl. 


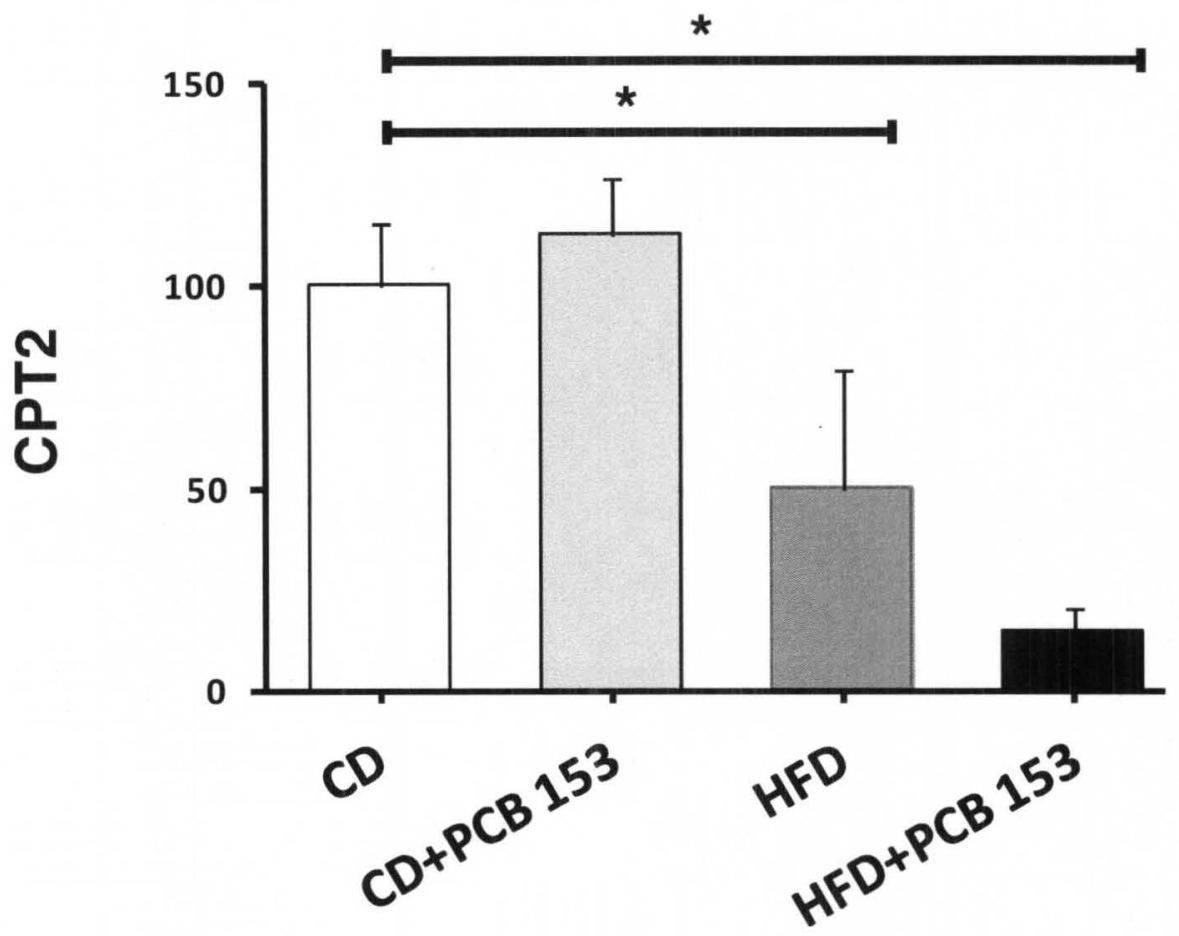

Figure 19. HFD and PCB exposure altered expression of CPT2 in liver.

Real-time PCR experiments showed the changes in hepatic mRNA expressions for carnitine palmitoyl transferase 2 (CPT2) in mice liver caused by either PCB 153 exposure or HFD consumption or both as compared to gene expression in mice fed CD without or with PCB 153 exposure. All values were normalized to CD group, $(n=10)$. Data are expressed as mean \pm SEM. ${ }^{*} P<0.05$. CD-control diet, HFD-high fat diet, PCB-polychlorinated biphenyl. 
The role of PCB 153 in endoplasmic reticulum stress.

Our RT-PCR studies on the adipose tissue of C57BI/6 mice fed either CD or HFD with or without PCB 153 co-administration showed interesting results that suggested the role of PCBs as ER stress inducers in the presence of HFD. RTPCR was performed on mRNA extracted from the mouse adipose tissue for adiponectin, CHOP 10, C/EBPa and PPARY.

Adiponectin mRNA levels decreased significantly in the HFD+PCB 153 group $(2.77 \pm 1.06)$ and HFD+vehicle group $(24.90 \pm 16.92)$ when compared to CD+vehicle $(100 \pm 23.66, p<0.05)$ (Figure 20). CHOP 10 mRNA expression increased significantly in the HFD+vehicle $(610.89 \pm 194.73)$ and HFD+PCB 153 group $(325.66 \pm 139.06)$ vs. CD+vehicle $(100 \pm 37.30, p<0.05)$ (Figure 21). C/EBPa showed a trend towards lower mRNA expression in HFD+vehicle and HFD+PCB 153 groups when compared to $C D+$ vehicle or $C D+P C B 153$ groups (Figure 22). PPARy mRNA expression (Figure 23) decreased significantly for the HFD+PCB 153 group $(11.42 \pm 2.43)$ as compared to CD+vehicle group (100 \pm $39.40, p<0.05)$, suggesting a probable ER-stress response in these animals. 


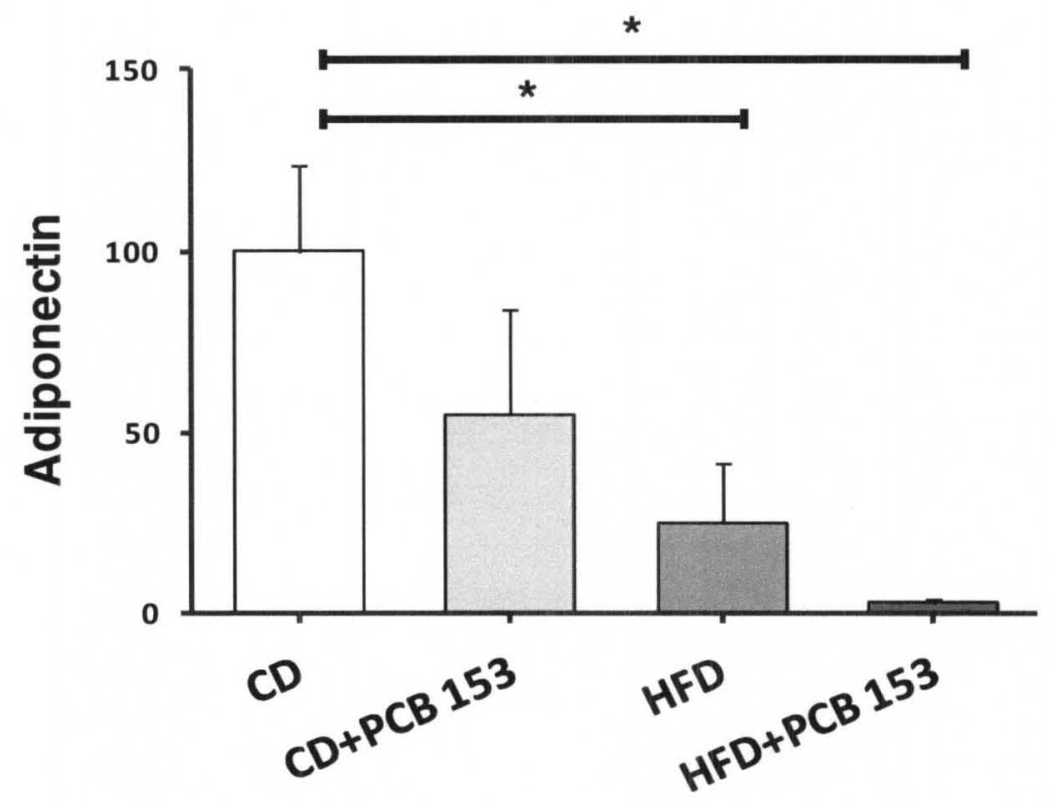

Figure 20. HFD and PCB exposure altered expression of adiponectin in adipose tissue.

Real-time PCR experiments showed the changes in adiponectin mRNA expression in the adipose tissue caused by either PCB 153 exposure or HFD consumption or both as compared to gene expression in mice fed CD without or with PCB 153 exposure. All values were normalized to CD group, $(n=5)$. Data are expressed as mean \pm SEM. ${ }^{*} \mathrm{P}<0.05$. CD-control diet, HFD-high fat diet, PCBpolychlorinated biphenyl. 


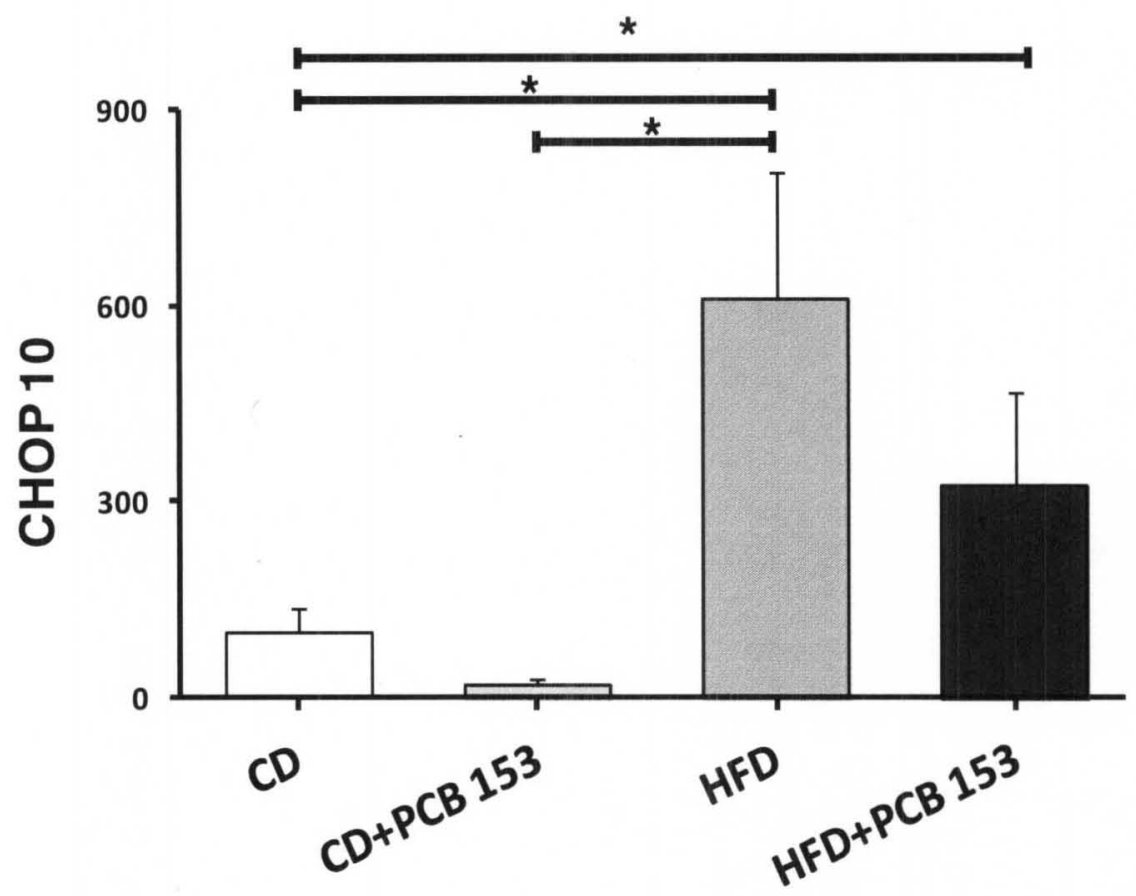

Figure 21. HFD and PCB exposure altered expression of CHOP 10 in adipose tissue.

Real-time PCR experiments showed the changes in CHOP 10 mRNA expression in the adipose tissue caused by either PCB 153 exposure or HFD consumption or both as compared to gene expression in mice fed CD without or with PCB 153 exposure. All values were normalized to CD group, $(n=6)$. Data are expressed as mean \pm SEM. ${ }^{*} \mathrm{P}<0.05$. CD-control diet, HFD-high fat diet, PCB-polychlorinated biphenyl. 


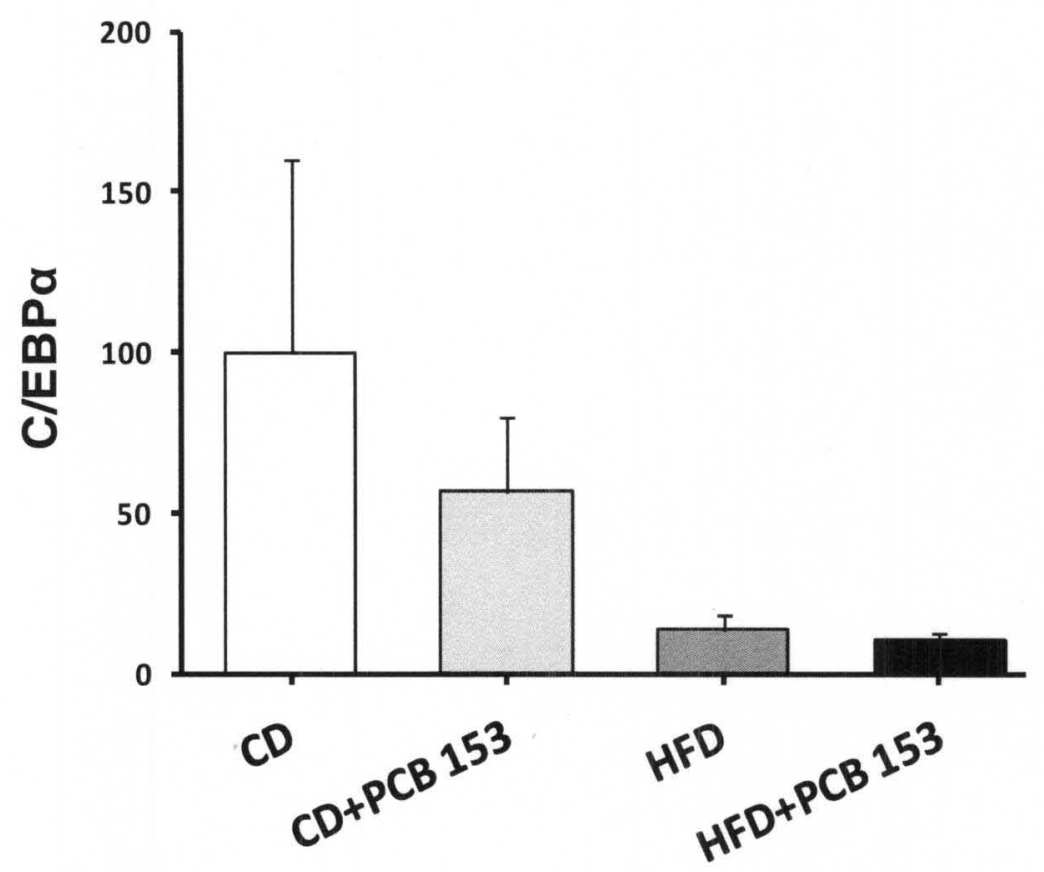

Figure 22. HFD and PCB exposure altered expression of C/EBPa in adipose tissue.

Real-time PCR experiments showed the changes in C/EBPa mRNA expression in the adipose tissue caused by either PCB 153 exposure or HFD consumption or both as compared to gene expression in mice fed CD without or with PCB 153 exposure. All values were normalized to CD group, $(n=4)$. Data are expressed as mean \pm SEM.. CD-control diet, HFD-high fat diet, PCB-polychlorinated biphenyl. 


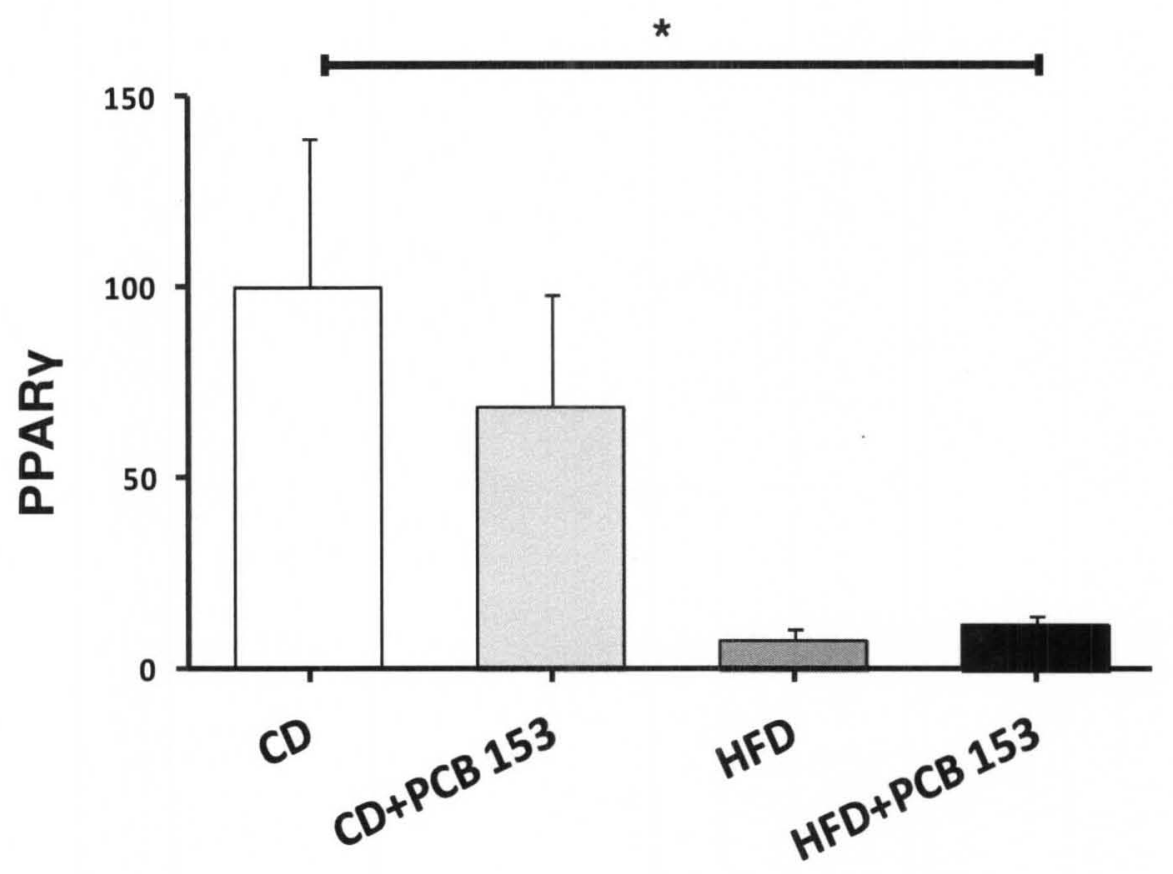

Figure 23. HFD and PCB exposure altered expression of PPARy in adipose tissue.

Real-time PCR experiments showed the changes in PPARy mRNA expression in the adipose tissue caused by either PCB 153 exposure or HFD consumption or both as compared to gene expression in mice fed CD without or with PCB 153 exposure. All values were normalized to $C D$ group, $(n=7)$. Data are expressed as mean \pm SEM. * $\mathrm{P}<0.05$. CD-control diet, HFD-high fat diet, PCB-polychlorinated biphenyl. 


\section{DISCUSSION}

PCBs are known to concentrate within adipose tissue and liver, so it is not surprising that these were the principal target sites for $\mathrm{PCB} 153$ toxicity in this study. Although PCB 153 levels were not measured, we expect them to be similar to those in the NTP TR 530 14-week study (16). The NTP protocol resulted in the following PCB 153 levels: lipid adjusted serum-1788 ng/g; liver$34,010 \mathrm{ng} / \mathrm{g}$; and adipose-1,118,300 ng/g. Thus, PCB 153 accumulates in the adipose tissue and is likely to exert its effects at this site.

In our results, PCB 153 exposure to the HFD group altered multiple adipokines including leptin, tPAI-1, resistin and adiponectin. Adiponectin, also referred to as GBP-28, apM1, AdipoQ or Acrp30, is an adipocyte-derived protein hormone which is encoded by the $A D I P O Q$ gene in humans (56). Adiponectin regulates glucose and fatty acid catabolism (57) and its plasma levels in adults are inversely proportional to body fat percentage (58). Literature reports have demonstrated adiponectin's role in suppressing metabolic derangements that can occur due to obesity (55), type 2 diabetes mellitus (58), atherosclerosis (57) and metabolic syndrome (59). Interestingly, the plasma levels of leptin were increased to a greater extent in the HFD+PCB 153 group as compared to adiponectin. Leptin, a $30 \mathrm{kDa}$ protein hormone encoded by the $O b(L e p)$ gene, is also secreted by the adipocytes and plays a crucial role in modulating energy intake and expenditure as well as appetite suppression (60, 61). Circulating levels of leptin are directly correlated with body fat mass and 
adipocyte size, with increasingly high levels seen in obesity (62). The overall increase in adiposity in the HFD+PCB 153 animals may be responsible for the increased circulating levels of leptin. Our results indicated that the observed disproportion of adiponectin to leptin increment in the plasma of animals treated with HFD+PCB 153 was due to increased adiposity and probably increased leptin /decreased adiponectin production in the adipose tissue.

Steatosis was dramatically increased by the combination of PCB 153+HFD, whereas PCB 153 had no effect in mice fed CD. Steatosis is determined by the rates of lipid synthesis, oxidation, uptake, and export. The RTPCR results suggest that PCB 153+HFD co-exposures increased hepatic lipid synthesis (up-regulated FAS) while decreasing $\beta$-oxidation (down-regulated CPT1A and CPT2 and its transcription factor, PPARa). Therefore, PCB 153 seemed likely to increase hepatic steatosis in mice fed HFD by altering adipokines, increasing hepatic lipid synthesis, and decreasing hepatic $\beta$ oxidation. This hypothesis will be investigated further in future studies.

RT-PCR results showed a marked decrease in adiponectin expression levels in the adipose tissue. Interestingly, adiponectin plasma levels were increased in this group. This can be explained by increased fat mass in these animals that led to overall higher adiponectin secretion while the adiponectin synthesis per fat cell was decreased. The resulting adiponectin mRNA expression observed in the adipose tissue led us to hypothesize that PCB 153 
may act as an ER stress inducer in the adipose tissue in the presence of HFD. We therefore looked at the mRNA expression of proteins that play a major role in ER stress response, namely, CHOP 10 which is upregulated in ER stress, $\mathrm{C} / \mathrm{EBPa}$, required for adipocyte differentiation and negatively regulated by $\mathrm{CHOP}$ 10, and PPARy, a positive transcription factor for adiponectin. Indeed, mRNA expression was increased for CHOP 10 and repressed for CEBPa. PPARy mRNA expression was also reduced in PCB 153-exposed mice fed with HFD.

In general, HFD consumption and PCB 153 co-exposure led to increased lipogenesis in the liver by upregulation of FAS, and a decrease in PPAR $\alpha$ mediated fatty acid- $\beta$-oxidation. Furthermore, there is evidence of adipokine dysregulation in the HFD+PCB 153 group. These finding s are important because they implicate PCB 153 exposure in hepatic steatosis and adipokine dysregulation, hallmarks of the metabolic syndrome. The presence of an ER stress response is also speculated in the adipose tissue due to low adiponectin secretion. However, this study requires further investigation. 


\section{SUMMARY}

PCBs are poly-halogenated hydrocarbons which are persistent contaminants in our environment. Exposure to PCBs including the ubiquitous PCB153 has been dose dependently linked to increased odds ratio for serum alanine aminotransferase elevation, indicative of NAFLD. To determine if PCB153 plays a casual role in the development of NAFLD, a study was undertaken to determine if PCB 153 either caused NALFD by itself or worsened NAFLD induced by HFD consumption.

It was observed that PCB153 exposure caused an increase in \% body weight for animals fed a HFD. PCB 153 exposure also caused micro-vesicular steatosis in animals fed a HFD and worsened HFD-induced macro-vesicular steatosis. Serum adipokines were increased with HFD and this effect was augmented by PCB 153 co-administration. PCB 153 treatment increased liver triglycerides and cholesterol levels in the HFD group of animals. FAS expression was upregulated and PPAR $\alpha$ expression downregulated in the liver of animals fed a HFD and co-exposed to PCB 153. The adiponectin mRNA level decreased in the HFD+PCB153 group. 
In conclusion, PCB 153 is a diet-dependent obesogen, which also worsens NAFLD via adipokine dysregulation and altered lipid metabolism. These experimental results suggest that the previously observed associations between PCB levels and human obesity/NAFLD may be causal. Nutrient-toxicant interactions in obesity, metabolic syndrome, and NAFLD/TASH warrant further study. 


\section{REFERENCES}

1. Breivik K, Sweetman A, Pacyna JM, Jones KC. Towards a global historical emission inventory for selected PCB congeners--a mass balance approach. 1. Global production and consumption. Sci Total Environ 2002;290:181-198.

2. Goncharov A, Bloom M, Pavuk M, Birman I, Carpenter DO. Blood pressure and hypertension in relation to levels of serum polychlorinated biphenyls in residents of Anniston, Alabama. J Hypertens 2010;28:2053-2060.

3. Schecter A, Colacino J, Haffner D, Patel K, Opel M, Papke O, Birnbaum L. Perfluorinated Compounds, Polychlorinated Biphenyl, and Organochlorine Pesticide Contamination in Composite Food Samples from Dallas, Texas. Environ Health Perspect 2010.

4. Cave M, Appana S, Patel M, Falkner KC, McClain CJ, Brock G. Polychlorinated biphenyls, lead, and mercury are associated with liver disease in american adults: NHANES 2003-2004. Environ Health Perspect 2010;118:1735-1742.

5. Cave M, Deaciuc I, Mendez C, Song Z, Joshi-Barve S, Barve S, McClain C. Nonalcoholic fatty liver disease: predisposing factors and the role of nutrition. J Nutr Biochem 2007;18:184-195.

6. Abdelmalek MF, Sanderson SO, Angulo P, Soldevila-Pico C, Liu C, Peter J, Keach J, et al. Betaine for nonalcoholic fatty liver disease: results of a randomized placebo-controlled trial. Hepatology 2009;50:1818-1826.

7. Seki E, Brenner DA. Toll-like receptors and adaptor molecules in liver disease: update. Hepatology 2008;48:322-335.

8. Meshkani R, Adeli K. Hepatic insulin resistance, metabolic syndrome and cardiovascular disease. Clin Biochem 2009;42:1331-1346. 
9. Browning JD, Horton JD. Molecular mediators of hepatic steatosis and liver injury. J Clin Invest 2004;114:147-152.

10. Chiang DJ, Pritchard MT, Nagy LE. Obesity, diabetes mellitus and liver fibrosis. Am J Physiol Gastrointest Liver Physiol 2011.

11. Cave M, Falkner KC, Ray M, Joshi-Barve S, Brock G, Khan R, Bon Homme $M$, et al. Toxicant-associated steatohepatitis in vinyl chloride workers. Hepatology 2010;51:474-481.

12. Ronn M, Lind L, van Bavel B, Salihovic S, Michaelsson K, Lind M. Circulating Levels of Persistant Organic Pollutants Associate in Divergent Ways to Fat Mass Measured by DXA in Humans. The Toxicologist CD Supplement to Toxicological Sciences - An Official Journal of the Society of Toxicology. 2011;120.

13. Lee DH, Lee IK, Porta M, Steffes M, Jacobs DR, Jr. Relationship between serum concentrations of persistent organic pollutants and the prevalence of metabolic syndrome among non-diabetic adults: results from the National Health and Nutrition Examination Survey 1999-2002. Diabetologia 2007;50:1841-1851.

14. Patel CJ, Bhattacharya J, Butte AJ. An Environment-Wide Association Study (EWAS) on type 2 diabetes mellitus. PLoS One 2010;5:e10746.

15. Lee DH, Lee IK, Song K, Steffes M, Toscano W, Baker BA, Jacobs DR, Jr. A strong dose-response relation between serum concentrations of persistent organic pollutants and diabetes: results from the National Health and Examination Survey 1999-2002. Diabetes Care 2006;29:1638-1644.

16. Cotrim HP, Andrade ZA, Parana R, Portugal M, Lyra LG, Freitas LA. Nonalcoholic steatohepatitis: a toxic liver disease in industrial workers. Liver 1999;19:299-304.

17. Uemura H, Arisawa K, Hiyoshi M, Kitayama A, Takami H, Sawachika F, Dakeshita $S$, et al. Prevalence of metabolic syndrome associated with body burden levels of dioxin and related compounds among Japan's general population. Environ Health Perspect 2009;117:568-573. 
18. Yu ML, Guo YL, Hsu CC, Rogan WJ. Increased mortality from chronic liver disease and cirrhosis 13 years after the Taiwan "yucheng" ("oil disease") incident. Am J Ind Med 1997;31:172-175.

19. Safe SH. Toxicology, Structure-Function Relationship, and Humana nd Environmental Health Impactsof Polychlorinated Biphenyls: Progress and Problems. Environmental Health Perspectives 1993;100:259-268.

20. NTP. NTP Toxicology and Carcinogenesis Studies of a Binary Mixture of 3,3',4,4',5-Pentachlorobiphenyl (PCB 126) (CAS No. 57465-28-8) and 2,2',4,4',5,5'-Hexachlorobiphenyl (PCB 153) (CAS No. 35065-27-1) in Female Harlan Sprague-Dawley Rats (Gavage Studies). Natl Toxicol Program Tech Rep Ser 2006:1-258.

21. Dean CE, Jr., Benjamin SA, Chubb LS, Tessari JD, Keefe TJ. Nonadditive hepatic tumor promoting effects by a mixture of two structurally different polychlorinated biphenyls in female rat livers. Toxicol Sci 2002;66:54-61.

22. Safe S, Bandiera S, Sawyer T, Robertson L, Safe L, Parkinson A, Thomas $P E$, et al. PCBs: structure-function relationships and mechanism of action. Environ Health Perspect 1985;60:47-56.

23. Hennig B, Reiterer G, Toborek M, Matveev SV, Daugherty A, Smart E, Robertson LW. Dietary fat interacts with PCBs to induce changes in lipid metabolism in mice deficient in low-density lipoprotein receptor. Environ Health Perspect 2005;113:83-87.

24. Lee JH, Wada T, Febbraio M, He J, Matsubara T, Lee MJ, Gonzalez FJ, et al. A novel role for the dioxin receptor in fatty acid metabolism and hepatic steatosis. Gastroenterology 2010;139:653-663.

25. Dere E, Lee AW, Burgoon LD, Zacharewski TR. Differences in TCDDelicited gene expression profiles in human HepG2, mouse Hepa1c1c7 and rat H4IIE hepatoma cells. BMC Genomics 2011;12:193.

26. Luthe G, Jacobus JA, Robertson LW. Receptor interactions by polybrominated diphenyl ethers versus polychlorinated biphenyls: a 
theoretical Structure-activity assessment. Environ Toxicol Pharmacol 2008;25:202-210.

27. NTP. NTP technical report on the toxicology and carcinogenesis studies of 2,2',4,4',5,5'-hexachlorobiphenyl (PCB 153) (CAS No. 35065-27-1) in female Harlan Sprague-Dawley rats (Gavage studies). Natl Toxicol Program Tech Rep Ser 2006:4-168.

28. NTP Toxicology and Carcinogenesis Studies of a Binary Mixture of 3,3', 4,4',5-Pentachlorobiphenyl (PCB 126) (CAS No. 57465-28-8) and 2,2',4,4',5,5'-Hexachlorobiphenyl (PCB 153) (CAS No. 35065-27-1) in Female Harlan Sprague-Dawley Rats (Gavage Studies). Natl Toxicol Program Tech Rep Ser 2006:1-258.

29. NTP Toxicology and Carcinogenesis Studies of a Binary Mixture of 3,3',4,4',5-Pentachlorobiphenyl (PCB 126) (CAS No. 57465-28-8) and 2,3',4,4',5-Pentachlorobiphenyl (PCB 118) (CAS No. 31508-00-6) in Female Harlan Sprague-Dawley Rats (Gavage Studies). Natl Toxicol Program Tech Rep Ser 2006:1-218.

30. Hennig B, Ettinger AS, Jandacek RJ, Koo S, McClain C, Seifried H, Silverstone $A$, et al. Using nutrition for intervention and prevention against environmental chemical toxicity and associated diseases. Environ Health Perspect 2007;115:493-495.

31. Brown JF. Determination of PCB Metabolic, Excretion, and Accumulation Rates for Use as Indicators of Biological Response and Relative Risk. Environ Sci Technol 1994;28:2295-2305.

32. Bandiera SM: Cytochrome P450 enzymes as biomarkers of PCB exposure and modulators of toxicity. In: Roberston LW, Lansen LG, eds. PCBs: Recent Advances in Environmental Toxicology and Health Effects, 2001; 185-192.

33. Livak KJ, Schmittgen TD. Analysis of relative gene expression data using real-time quantitative PCR and the 2(-Delta Delta $\mathrm{C}(\mathrm{T})$ ) Method. Methods 2001;25:402-408. 
34. NTP. NTP toxicology and carcinogenesis studies of $3,3^{\prime}, 4,4^{\prime}, 5-$ pentachlorobiphenyl (PCB 126) (CAS No. 57465-28-8) in female Harlan Sprague-Dawley rats (Gavage Studies). Natl Toxicol Program Tech Rep Ser 2006:4-246.

35. NTP. Toxicology and carcinogenesis studies of $2,3^{\prime}, 4,4^{\prime}, 5-$ pentachlorobiphenyl (PCB 118) (CAS No. 31508-00-6) in female harlan Sprague-Dawley rats (gavage studies). Natl Toxicol Program Tech Rep Ser 2010:1-174.

36. Flaveny CA, Perdew GH. Transgenic Humanized AHR Mouse Reveals Differences between Human and Mouse AHR Ligand Selectivity. Mol Cell Pharmacol 2009;1:119-123.

37. Kodama S, Koike C, Negishi M, Yamamoto Y. Nuclear receptors CAR and PXR cross talk with FOXO1 to regulate genes that encode drugmetabolizing and gluconeogenic enzymes. Mol Cell Biol 2004;24:79317940.

38. Lee DH, Steffes MW, Sjodin A, Jones RS, Needham LL, Jacobs DR, Jr. Low dose organochlorine pesticides and polychlorinated biphenyls predict obesity, dyslipidemia, and insulin resistance among people free of diabetes. PLoS One;6:e15977.

39. Kershner N, Stocker A, Falkner KC, McClain CJ, Cave M. Polychlorinated Biphenols (PCB) Induce Tumor Necrosis Factor a (TNFa) Production IN RAW 264.7 Cells [abstract]. The Toxicologist CD Supplement to Toxicological Sciences - An Official Journal of the Society of Toxicology. 2010;114(1)::743A.

40. Inoue M, Ohtake $T$, Motomura W, Takahashi N, Hosoki $Y$, Miyoshi S, Suzuki $Y$, et al. Increased expression of PPARgamma in high fat diet-induced liver steatosis in mice. Biochem Biophys Res Commun 2005;336:215-222.

41. Cnop M, Foufelle F, Velloso LA. Endoplasmic reticulum stress, obesity and diabetes. Trends Mol Med 2012;18:59-68. 
42. Li Y, Ge M, Ciani L, Kuriakose G, Westover EJ, Dura M, Covey DF, et al. Enrichment of endoplasmic reticulum with cholesterol inhibits sarcoplasmicendoplasmic reticulum calcium ATPase-2b activity in parallel with increased order of membrane lipids: implications for depletion of endoplasmic reticulum calcium stores and apoptosis in cholesterol-loaded macrophages. J Biol Chem 2004;279:37030-37039.

43. Wang XZ, Lawson B, Brewer JW, Zinszner H, Sanjay A, Mi LJ, Boorstein R, et al. Signals from the stressed endoplasmic reticulum induce C/EBPhomologous protein (CHOP/GADD153). Mol Cell Biol 1996;16:4273-4280.

44. Yoshida H, Okada T, Haze K, Yanagi H, Yura T, Negishi M, Mori K. ATF6 activated by proteolysis binds in the presence of NF-Y (CBF) directly to the cis-acting element responsible for the mammalian unfolded protein response. Mol Cell Biol 2000;20:6755-6767.

45. Lawrence MC, McGlynn K, Naziruddin B, Levy MF, Cobb MH. Differential regulation of CHOP-10/GADD153 gene expression by MAPK signaling in pancreatic beta-cells. Proc Natl Acad Sci U S A 2007;104:11518-11525.

46. Ma Y, Brewer JW, Diehl JA, Hendershot LM. Two distinct stress signaling pathways converge upon the $\mathrm{CHOP}$ promoter during the mammalian unfolded protein response. J Mol Biol 2002;318:1351-1365.

47. Fawcett TW, Martindale JL, Guyton KZ, Hai T, Holbrook NJ. Complexes containing activating transcription factor (ATF)/cAMP-responsive-elementbinding protein (CREB) interact with the CCAAT/enhancer-binding protein (C/EBP)-ATF composite site to regulate Gadd153 expression during the stress response. Biochem J 1999;339 (Pt 1):135-141.

48. Tang QQ, Lane MD. Role of C/EBP homologous protein (CHOP-10) in the programmed activation of CCAAT/enhancer-binding protein-beta during adipogenesis. Proc Natl Acad Sci U S A 2000;97:12446-12450.

49. McCullough KD, Martindale JL, Klotz LO, Aw TY, Holbrook NJ. Gadd153 sensitizes cells to endoplasmic reticulum stress by down-regulating $\mathrm{Bcl} 2$ and perturbing the cellular redox state. Mol Cell Biol 2001;21:1249-1259. 
50. Timchenko NA, Wilde M, Nakanishi M, Smith JR, Darlington GJ. CCAAT/enhancer-binding protein alpha (C/EBP alpha) inhibits cell proliferation through the p21 (WAF-1/CIP-1/SDI-1) protein. Genes Dev 1996;10:804-815.

51. Altiok S, Xu M, Spiegelman BM. PPARgamma induces cell cycle withdrawal: inhibition of E2F/DP DNA-binding activity via down-regulation of PP2A. Genes Dev 1997;11:1987-1998.

52. Ron D, Habener JF. CHOP, a novel developmentally regulated nuclear protein that dimerizes with transcription factors C/EBP and LAP and functions as a dominant-negative inhibitor of gene transcription. Genes Dev 1992;6:439-453.

53. Clarke SL, Robinson CE, Gimble JM. CAAT/enhancer binding proteins directly modulate transcription from the peroxisome proliferator-activated receptor gamma 2 promoter. Biochem Biophys Res Commun 1997;240:99103.

54. Kita A, Yamasaki H, Kuwahara H, Moriuchi A, Fukushima K, Kobayashi M, Fukushima $T$, et al. Identification of the promoter region required for human adiponectin gene transcription: Association with CCAAT/enhancer binding protein-beta and tumor necrosis factor-alpha. Biochem Biophys Res Commun 2005;331:484-490.

55. Kim JY, van de Wall E, Laplante M, Azzara A, Trujillo ME, Hofmann SM, Schraw $T$, et al. Obesity-associated improvements in metabolic profile through expansion of adipose tissue. J Clin Invest 2007;117:2621-2637.

56. Maeda K, Okubo K, Shimomura I, Funahashi T, Matsuzawa Y, Matsubara K. cDNA cloning and expression of a novel adipose specific collagen-like factor, apM1 (AdiPose Most abundant Gene transcript 1). Biochem Biophys Res Commun 1996;221:286-289.

57. Diez JJ, Iglesias $\mathbf{P}$. The role of the novel adipocyte-derived hormone adiponectin in human disease. Eur J Endocrinol 2003;148:293-300. 
58. Ukkola O, Santaniemi M. Adiponectin: a link between excess adiposity and associated comorbidities? J Mol Med (Berl) 2002;80:696-702.

59. Renaldi O, Pramono B, Sinorita H, Purnomo LB, Asdie RH, Asdie AH. Hypoadiponectinemia: a risk factor for metabolic syndrome. Acta Med Indones 2009;41:20-24.

60. Zhang Y, Proenca R, Maffei M, Barone M, Leopold L, Friedman JM. Positional cloning of the mouse obese gene and its human homologue. Nature 1994;372:425-432.

61. Zhang F, Basinski MB, Beals JM, Briggs SL, Churgay LM, Clawson DK, DiMarchi RD, et al. Crystal structure of the obese protein leptin-E100. Nature 1997;387:206-209.

62. Houseknecht KL, Baile CA, Matteri RL, Spurlock ME. The biology of leptin: a review. J Anim Sci 1998;76:1405-1420. 


\section{CURRICULUM VITAE}

\section{BANRIDA WAHLANG}

Date of Birth: March 161986

Birth Place: Shillong, India

Email address: b0wahl01@ louisville.edu

\section{EDUCATION}

Master of Science, Pharmacology \& Toxicology,

2010-Present

University of Louisville

MS (Pharmaceutics), NIPER

June 2010

Bachelors (Pharmacy), University of Delhi

June 2008

\section{ABSTRACTS}

1. 2009- Wahlang B, Pawar YB, Patil SR and Bansal AK. The Caco-2 Cell Model: A Useful Tool in Drug Discovery and Development. CRIPS 2009, 10(2), 29-34. (Apr-Jun).

2. HPLC method for determination of curcumin for its application in Caco-2 permeability assays. B. Wahlang, Y.B. Pawar, A.K. Bansal. IPC, 2009.

3. Determination of curcumin's permeability using the Caco-2 cell model. B. Wahlang, Y.B. Pawar, A.K. Bansal. DMPK, 2010. 
4. Intestinal transport mechanism of a novel thyrotropin releasing hormone. $\mathrm{K}$ Khomane, B. Wahlang, Y.B. Pawar, C.L. Meena, R. Jain, A.K. Bansal. DMPK, 2011.

5. Polychlorinated Biphenyl 153 worsens non-alcoholic fatty liver disease in C57BL/6 mice. B. Wahlang, K.C. Falkner, D.J. Conklin, C.J. McClain, M. Cave. OVSOT 2011.

6. A comparison of serum adipocytokines, cytokeratin 18, and antioxidants in human subjects with steatohepatitis due to alcohol (ASH), obesity (NASH), and industrial chemicals (TASH). H. Shah, B. Wheeler, Y. Mannery, K.C. Falkner, B. Wahlang, C.J. McClain, M. Cave. Research! Louisville, 2011.

7. Polychlorinated Biphenyl 153 worsens hepatic steatosis in mice fed a high fat diet and differentially regulates 40 liver metabolites: preliminary results of a metabolomics analysis. B. Wahlang, X. Zhang, K. C. Falkner, C. J. McClain, M. Cave. AASLD, 2011.

8. The metabolic effects of PCB 153 depend on nutrient interactions in obesity/nonalcoholic fatty liver disease. B. Wahlang, X. Shi, X. Zhang, K.C. Falkner, C.J. McClain, R. Prough, M. Cave. Digestive Disease Week, 2012.

\section{PUBLICATIONS}

1. Identification of permeability-related hurdles in oral delivery of curcumin using the Caco-2 cell model. Eur. J Pharm. Biopharm. 2011, 77(2): 275-82.

2. The Persistent Environmental Pollutant, Polychlorinated Biphenyl 153, Exacerbates Nonalcoholic Fatty Liver Disease in C57BL/6 Mice. B. 
Wahlang, K. C. Falkner, B. Gregory, D. Ansert, D. Young, D. J. Conklin, C. J. McClain, Aruni Bhatnagar, M. Cave. 2012. (Under Review).

3. Metabolomic Analysis of the Effects of Polychlorinated Biphenyls in Nonalcoholic Fatty Liver Disease. X. Shi, B. Wahlang, X. Wei,X. Yin,K. C. Falkner, R. A. Prough,S. Ho Kim, C. J. McClain, M. Cave, X. Zhang. 2012. (Under Review).

\section{PROFESSIONAL MEMBERSHIPS/POSITIONS}

Member, Indian Pharmaceutical Graduate Association (IPGA). 2006-2008 Secretary, Pharmaceutics Club, NIPER. $2009-2010$ Member, American Association of Pharmaceutical Scientists (AAPS) NIPER Students Chapter. $2009-2010$

Public Relations Officer, American International Relations Club (AIRC), University of Louisville. 2011-Present

Member, Indian Students Association, University of Louisville. $\quad$ 2011-Present Member, Kentucky Academy of Science. 2012-Present 